\title{
Effect of polyamide-6,6 (PA 66) nonwoven veils on the mechanical performance of carbon fiber/epoxy composites
}

\author{
Bertan Beylergil $^{\mathrm{a}}$, Metin Tanoğlu ${ }^{\mathrm{a}, *}$, Engin Aktaş ${ }^{\mathrm{b}}$ \\ ${ }^{a}$ Faculty of Engineering, Department of Mechanical Engineering, Izmir Institute of Technology, Izmir, Turkey \\ ${ }^{\mathrm{b}}$ Faculty of Engineering, Department of Civil Engineering, Izmir Institute of Technology, Izmir, Turkey
}

\section{A R T I C L E I N F O}

\section{Keywords:}

PA66 nonwoven interleaving

Delamination

Fracture toughness

Laminated composites

\begin{abstract}
A B S T R A C T
In this study, carbon fiber/epoxy (CF/EP) composites were interleaved with polyamide-6,6 (PA 66) nonwoven veils at two different areal weight densities (17 and $50 \mathrm{gsm})$ to improve their delamination resistance against Mode-I loading. Mode-I fracture toughness (DCB), tensile, open hole tensile (OHT), flexural, compression, short beam shear (ILSS) and Charpy-impact tests were performed on the reference and PA 66 interleaved composite specimens. The DCB test results showed that the initiation and propagation Mode-I fracture toughness values of the composites were significantly improved by 84 and 171\% using PA 66-17 gsm veils respectively, as compared to reference laminates. The use of denser PA $66-50 \mathrm{gsm}$ veils in the interlaminar region led to higher improvement in fracture toughness values (349\% for initiation and $718 \%$ for propagation) due to the higher amount of veil fibers involved in fiber bridging toughening mechanism. The incorporation of PA 66-50 gsm nonwoven veils also increased the ILSS and Charpy impact strength of the composites by 25 and $15 \%$, respectively. On the other hand, the PA 66 veils reduced in-plane mechanical properties of CF/EP composites due to lower carbon fiber volume fraction and increased thickness.
\end{abstract}

\section{Introduction}

$\mathrm{CF} / \mathrm{EP}$ composites have been extensively used in many engineering applications due to their unique advantages such as high strength and stiffness at low weight, good corrosion resistance and fatigue properties. However, they are susceptible to delamination damage during their service life. Delamination, the separation of two adjacent plies, may occur due to low-velocity impact events, manufacturing imperfections and stress concentrations triggered by sudden changes in structural details. This failure mode provokes severe reductions in the in-plane stiffness and strength values which result in accelerated growth of damage and premature failure. Also, CF/EP composites become more vulnerable to moisture uptake and contaminant penetration due to delamination. Therefore, delamination resistance of these materials needs to be improved for promoting their widespread acceptance in the aerospace, automotive and wind-energy industries [1,2].

The focus of various researchers has been the improvement of the delamination resistance of high performance fiber reinforced composites. There are two different approaches to preventing delamination failure in these composites; (i) mechanical approach and (ii) material approach. Mechanical approach includes weaving, stitching, z-anchoring and braiding of the composite plies. This approach was shown to be very successful in improving delamination resistance of fiber-reinforced composites. For instance, interlaminar fracture toughness (IFT) can be enhanced by $20-50$ times via stitching. Although Z-anchoring is only applicable for prepreg laminates, it increases IFT significantly (up to $470 \%$ ). On the other hand, these modifications cause significant reductions in in-plane mechanical properties of the composites [3]. Steeves and Fleck [4] showed that the presence of z-pins reduced the tensile and compressive strength of the composites by 37 and $30 \%$, respectively. Reeder [5] revealed that the tensile strength of the composites decreased about 30\% after stitching operation. Also, Kang and Lee [6] showed that increasing density of stitching for higher delamination resistance reduced tensile strength and modulus of the composites by $45 \%$ and $30 \%$ respectively. It was also shown that the in-plane tension, compression and flexural properties of the 3D woven composites made by weaving or braiding were 10 to $45 \%$ lower than those of the reference composites $[7,8]$. Moreover, these techniques do not hinder the initiation of damage; only enhance the resistance to crack growth once the damage has initiated. In material approach, different types of micro or nano-sized fillers such as alumina, silica, carbon black, graphene, carbon nanotubes (CNTs) are mixed/stirred/sonicated with the matrix phase for improving delamination resistance. The increase in IFT achieved by filler addition can be in the range between 15 and

\footnotetext{
* Corresponding author.

E-mail address: metintanoglu@iyte.edu.tr (M. Tanoğlu).
} 
$100 \%$ depending on the filler type and its content in the resin. Yokozeki et al. [9] showed that the IFT of composite laminates containing short cup-stacked carbon nanotubes (CSCNTs) was 200\% higher than the unmodified ones. Recently, Ragosta et al. [10] used silica nanoparticles to toughen epoxy matrix and obtained $288 \%$ increase in IFT of composites. To the best of authors' knowledge, this is the highest improvement reported in the literature. However, this approach has some clear drawbacks such as enormously increased resin viscosity and nonuniform distribution of fillers in resulting laminates due to the filtration effects of reinforcing fabrics during the resin infusion.

Most recently, interleaving technique, based on insertion of an interleaf material at the interlaminar region, has been developed by some researchers. Various interleaf materials such as thermoplastic and thermoset films, micro or nanofiber nonwoven veils and self-same resin interleaf materials have been studied [11-17]. Compared to filler toughening, this technique does not increase the uncured resin viscosity and the veil fibers are uniformly distributed in the resulting laminate. The use of toxic and/or harmful, and also expensive fillers such as CNTs and graphene is not necessary in this technique. Also, the initial investment and maintenance cost of industrial textile machines used for weaving and stitching is not an issue in this technique, which leads to significant financial savings. Saz-Orozco et al. [18] investigated the effects of polyamide (PA) and polyethylene terephthalate (PET) veils on the interlaminar fracture toughness (IFT) of a glass fiber/vinyl ester (GF/VE) composite. They showed that PET veils had no significant effect on the IFT of composites while PA veils increased the mode I interlaminar fracture toughness values at crack initiation and propagation levels improved by 59 and 90\%, respectively. Fitzmaurice et al. [19] also showed that PET veils were not effective for improving Mode-I interlaminar fracture toughness of the glass fiber/ polyester resin (GF/ $\mathrm{PE}$ ) composites due to the weaker glass/resin interface providing an alternative crack propagation path. They also showed that the incorporation of PET veils had positive effects on the flexural strength, interlaminar shear strength and damping properties of the composites. Another study by Hamer et al. [20] showed that Mode-I fracture toughness could be increased by $326 \%$ with the inclusion of PA66 veils. O'Donovan et al. [21] showed that the maximum $\mathrm{G}_{\mathrm{IC}}$ for crack propagation of a PA interleaved composite increased by almost $170 \%$ over the baseline GF/PE composite. Miller et al. [22] observed a $40 \%$ increase in $\mathrm{G}_{\mathrm{IC}}$ with the addition of polyurethane (PU) veil. In all of these studies [18-22], the researchers investigated the effects of microfiber nonwoven veils on the fracture toughness of fiber reinforced composites, while other researchers went further and investigated the effects of electrospun nanofiber nonwoven veils on the delamination resistance of these composites. Although different types of nanofiber veils such as polyacrylonitrile (PAN) [23], polycaprolactone (PCL) [24] and polysulfone (PSF) [25] were studied in the literature, the majority of studies have focused on electrospun PA 66 nonwoven veils due to their high melting temperature $\left(260^{\circ} \mathrm{C}\right)$, good compatibility with uncured resin and good mechanical properties [26]. Beckermann and Pickering [27] showed that the use of a $9.0 \mathrm{gsm}$ (grams per square meter) electrospun PA 66 nonwoven veil improved Mode-I fracture toughness about 1.7 times. They also showed that there is a proportional relationship up to some point between the amount of nanofibers in the interlaminar region and Mode-I fracture toughness. Similar results were obtained in our recent study [28]. In the review article by Palazetti and Zucchelli [29] the effects of electrospun nanofiber nonwoven veils on the mechanical performance of composite laminates were summarized. Another study by Nash et al. [30] systematically reviewed the thermoplastic toughening techniques for thermosetting carbon fiber-reinforced composites.

Although some studies exist in the literature on the effects microfiber PA 66 veils on Mode-I fracture toughness of composites. Further research is needed to clarify the effects of these veils on the other mechanical and thermomechanical properties of existing CF/EP composites. This is the most comprehensive report investigating the effects of PA66 nonwoven interleaving on the mechanical properties of the carbon fiber/epoxy composites manufactured by vacuum-infusion technique. The present study also provides contribution for the questions regarding the effects of these veils on thermomechanical behavior of these composites. This study aims to make a unique contribution on this research gap and develop a better understanding of the effects of PA 66 nonwoven veils on the mechanical performance of the composites.

In this study, CF/EP composites were interleaved with PA 66 nonwoven veils to improve their Mode-I fracture toughness. Glass transition and melting temperature of the PA 66 veils were determined by differential scanning calorimetry (DSC). The reference and PA 66 interleaved specimens were manufactured by vacuum-infusion with $[0]_{4}$ orientation. A series of mechanical tests such as Mode-I (DCB) fracture toughness, tensile, OHT, flexural, compression, ILSS and Charpy-impact tests were carried out on the reference and interleaved specimens to reveal the potential of microfiber PA66 nonwoven interleaving system for composite structures.

\section{Experimental}

\subsection{Materials}

Unidirectional carbon fabrics with a fiber areal weight of $350 \mathrm{~g} / \mathrm{m}^{2}$ (Kordsa Global Inc. of Turkey) were used as the reinforcement material. The epoxy resin (Momentive ${ }^{\mathrm{TM}} \mathrm{L160}$ ) and its hardener (Momentive ${ }^{\mathrm{TM}}$ H160) were used with the weight ratio of 80:20, respectively. Commercial PA 66 veils (N-Fusion ${ }^{\mathrm{TM}}$ ) at two different areal densities (17 and $50 \mathrm{gsm}$ (grams per square meter)) were provided by Cerex Advanced Fabrics Inc., USA. SEM images of the PA 66 veils are shown in Fig. 1. The fiber diameter distribution was determined by measuring at least 25 fibers per sample using ImageJ software (National Institute of Mental Health, Bethesda, MD, USA). The average fiber diameter was determined as $19.94 \pm 1.79 \mu \mathrm{m}$.

The thickness of PA 66-17 and PA 66-50 gsm veils were $80 \mu \mathrm{m}$ and $150 \mu \mathrm{m}$, respectively. Differential scanning calorimetry (DSC) was used to determine the melting point and glass transition temperature $\left(\mathrm{T}_{\mathrm{g}}\right)$ of the PA 66 veils. The samples were heated from room temperature to $350{ }^{\circ} \mathrm{C}$ at a heating rate of $10^{\circ} \mathrm{C} / \mathrm{min}$ under a nitrogen atmosphere. Fig. 2 shows the DSC curve of the PA 66 veils. The melting and glass transition temperature of the PA 66 veils were determined as $259.3^{\circ} \mathrm{C}$ and $67.02{ }^{\circ} \mathrm{C}$, respectively.

\subsection{Manufacturing of composite test specimens}

The reference and PA 66 veil interleaved composite laminates were fabricated by vacuum-infusion technique with a $[0]_{4}$ fiber orientation. Fig. 3 shows schematic representation of the reference and PA 66 veil interleaved composite laminates. For DCB laminates, single PA 66 veil was placed between second and third plies before resin infusion. A nonadhesive film with a thickness of $20-25 \mu \mathrm{m}$ was inserted in the middle of the plies to form an initial crack along the interlaminar region of the DCB specimens. To determine other mechanical properties, PA 66 interleaved composite laminates were manufactured by placing a layer of PA 66 veil between each carbon fabric before resin infusion.

The composite laminates with/without PA 66 veils were manufactured under the same vacuum bag in order to get more consistent test results and observe the effects of these veils on the resin flow during vacuum infusion. Based on the visual observations during the filling stage from the resin inlet to the vacuum outlet, no change of the resin flow and flow rate was detected due to the PA 66 veils. Demolding of the manufactured composites was carried out after complete curing at room temperature, followed by a post curing in an oven at $60^{\circ} \mathrm{C}$ for $15 \mathrm{~h}$. The fabricated composites were cut into desired dimensions using abrasive water-jet system. The thickness of the specimens $(h)$ was measured to be in the range of $1.24-1.71 \mathrm{~mm}$. The fiber volume fraction 

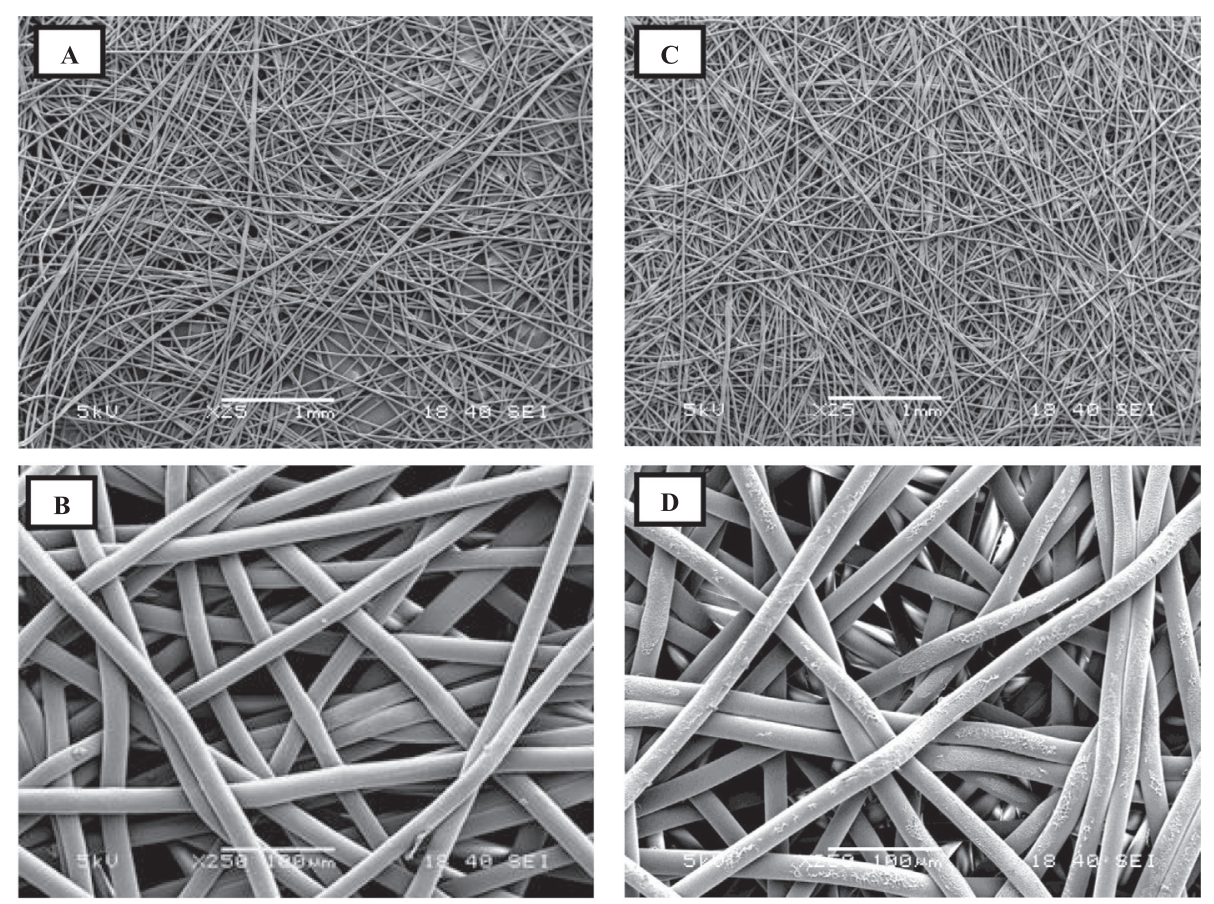

Fig. 1. SEM images of (a-b) $17 \mathrm{gsm}$ and (c-d) $50 \mathrm{gsm}$ PA 66 veils.

$\left(V_{f}\right)$ of the specimens was determined using the Archimedes principle. The incorporation of PA 66-17 and PA 66-50 gsm veils caused a decrease in the carbon fiber volume fraction about of 16.4 and $32.7 \%$ respectively. Table 1 shows the resulting laminate thickness and calculated fiber volume fraction of the specimens.

Fig. 4 shows SEM images of cross-sectional view of PA 66 interleaved composite specimens. The region between carbon plies, shown by the red lines, contains randomly oriented veil fibers which is totally filled with the epoxy matrix. These figures indicate the good wetting and impregnation of the veil fibers by the epoxy resin.

\subsection{Mechanical testing}

All mechanical tests were performed at ambient conditions in accordance with the relevant ASTM standards. At least five specimens were tested as recommended in the ASTM standards. The tensile tests were carried out at a constant crosshead speed of $2.0 \mathrm{~mm} / \mathrm{min}$ up to failure. A clip-on extensometer with knife edges was used to measure the strain. Instead of using rectangular specimens, dumbell-like shape specimens were prepared and tested to prevent failure that might occur near the end tabs. Tensile gripping end tabs were attached to reduce stress concentrations in the grip areas. Fig. 5(a) shows the geometry of the tensile test specimens used in this study. The stress concentration factor was calculated as 1.30 due to the curved length in the specimens.

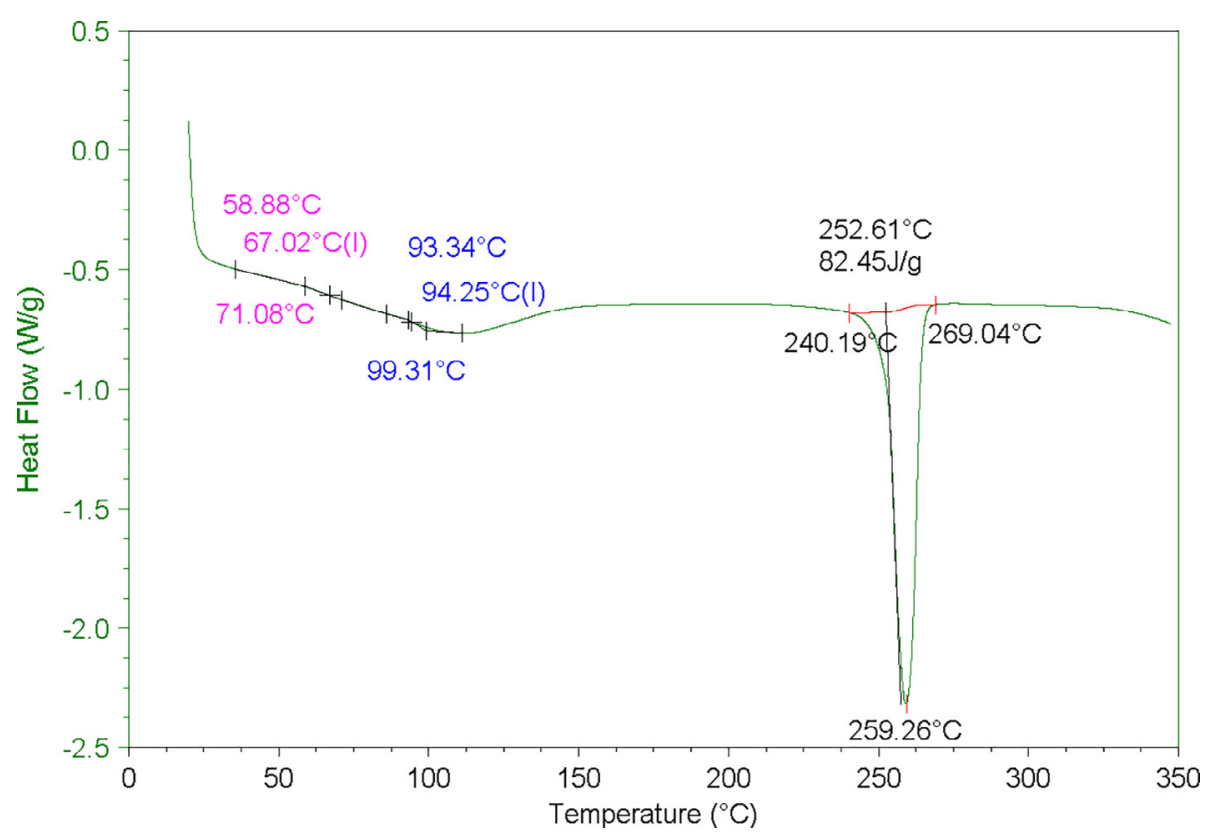

Fig. 2. DSC curve of the PA66 veils. 


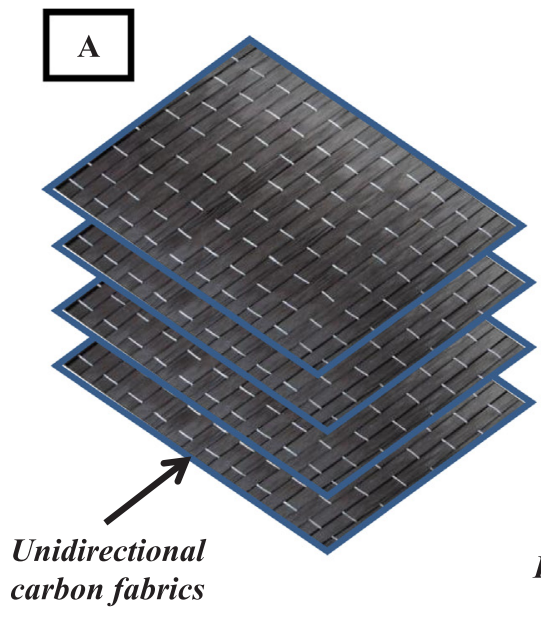

$\boldsymbol{P A}$

PA 66 nonwoven veils

B
Fig. 3. Schematic representation of the (a) reference (b) PA 66 nonwoven 1 interleaved composite laminates.
Table 1

Fiber volume fraction $\left(\mathrm{V}_{\mathrm{f}}\right)$ and average thickness of the composite laminates.

\begin{tabular}{llll}
\hline $\begin{array}{l}\text { Specimen Carbon } \\
\text { fiber/epoxy }\end{array}$ & $\begin{array}{l}\text { Veils in } \\
\text { composite (wt. } \\
\%)\end{array}$ & $\begin{array}{l}\text { The average } \\
\text { thickness }(\mathrm{mm})\end{array}$ & $\begin{array}{l}\text { Fiber volume } \\
\text { fraction }\left(\mathrm{V}_{\mathrm{f}}, \%\right)\end{array}$ \\
\hline $\begin{array}{l}\text { Reference } \\
\text { PA 66 17 gsm } \\
\text { interleaved }\end{array}$ & - & $1.24 \pm 0.009$ & $55 \pm 2.4$ \\
$\begin{array}{c}\text { PA 66 50 gsm } \\
\text { interleaved }\end{array}$ & 7.6 & $1.46 \pm 0.013$ & $46 \pm 1.0$ \\
\hline
\end{tabular}

A detailed information about the geometry of the tensile specimens can be found in Refs. [31,32]. Fig. 6 shows a tensile test specimen before and after tensile loading. In order to determine shear modulus $\left(\mathrm{G}_{12}\right)$, the composite specimens were cut at a $45^{\circ}$ orientation and tested under tension at a crosshead speed of $2.0 \mathrm{~mm} / \mathrm{min}$. First, $E_{x}$ was determined then $G_{12}$ was calculated by using the following formula [33];

$G_{12}=\frac{1}{\left(\frac{4}{E_{x}}-\frac{1}{E_{1}}-\frac{1}{E_{2}}+\frac{2 v_{12}}{E_{1}}\right)}$

where $E_{1}$ and $E_{2}$ represent the longitudinal and transverse modulus respectively. $v_{12}$ is the Poisson's ratio in plane of $1-2$. In the literature, the value of $v_{12}$ of unidirectional carbon fiber/epoxy composites is reported between 0.27 and 0.32 [34]. Based on this information, the $v_{12}$ of the composite specimens was considered as 0.27 in this study.

The open hole tensile strength (OHT) is one of the most critical mechanical properties especially for the design of composite riveted and bolted joints. In this study, OHT tests were also carried out on the reference and PA 66 interleaved specimens. The OHT specimen dimensions were $180 \mathrm{~mm}$ in length $(L)$ and $20 \mathrm{~mm}$ in width $(w)$. A 4-mm hole (d) was drilled in each specimen at its center. The gripping length ( $\mathrm{L}_{\text {gripping }}$ ) was $50 \mathrm{~mm}$. In-plane scaling of the composite specimens with respect to the hole diameter was shown in Fig. 5b. The OHT tests were performed at a crosshead speed of $1.25 \mathrm{~mm} / \mathrm{min}$ up to failure (Fig. 7a). In this case, gripping end tabs were not used because the stress concentration was high enough due to the drilled hole. The ultimate OHT of the specimens was calculated dividing maximum force by the gross cross sectional area (disregarding the hole).

The compressive strength and modulus of the specimens were determined using an anti-buckling fixture (Fig. 7b). The dimensions of the compression test specimens were $140 \mathrm{~mm}$ in length and $12.7 \mathrm{~mm}$ in width. The gauge length was $12.7 \mathrm{~mm}$. The specimens were loaded until failure at a constant crosshead speed of $1.3 \mathrm{~mm} / \mathrm{min}$. The flexural properties of the reference and PA 66 interleaved specimens were obtained from three point bending tests (Fig. 7c). A span-to-thickness ratio of 32:1 was used on the test fixture. The rate of crosshead motion was calculated for each group of specimens as recommended in the ASTM standard. The interlaminar shear strength (ILSS) tests were determined using the short beam shear test. A span-to-thickness ratio of 8:1 was used with a span of $10 \mathrm{~mm}$ on the test fixture. The test speed was $1.0 \mathrm{~mm} / \mathrm{min}$. Charpy impact tests were carried out according to ISO179 standard on $10 \times 80 \mathrm{~mm}$ rectangular notched specimens, using the CEAST $^{\circledR}$ Resil Impactor having maximum hammer energy of $15 \mathrm{~J}$ and hammer tangential speed of $3.46 \mathrm{~m} / \mathrm{s}$.

The Mode-I interlaminar fracture toughness of the composites was determined by double cantilever beam (DCB) experiments. The configuration of the specimens for DCB testing was shown in Fig. 8. The dimensions of the DCB test specimens were $\mathrm{L}=150 \mathrm{~mm}$ in length and $\mathrm{b}=25 \mathrm{~mm}$ in width. Aluminum blocks were bonded to outer surfaces of the DCB specimens to transfer the opening forces. Each specimen was initially loaded with a crosshead speed of $1 \mathrm{~mm} / \mathrm{min}$ and the crack was
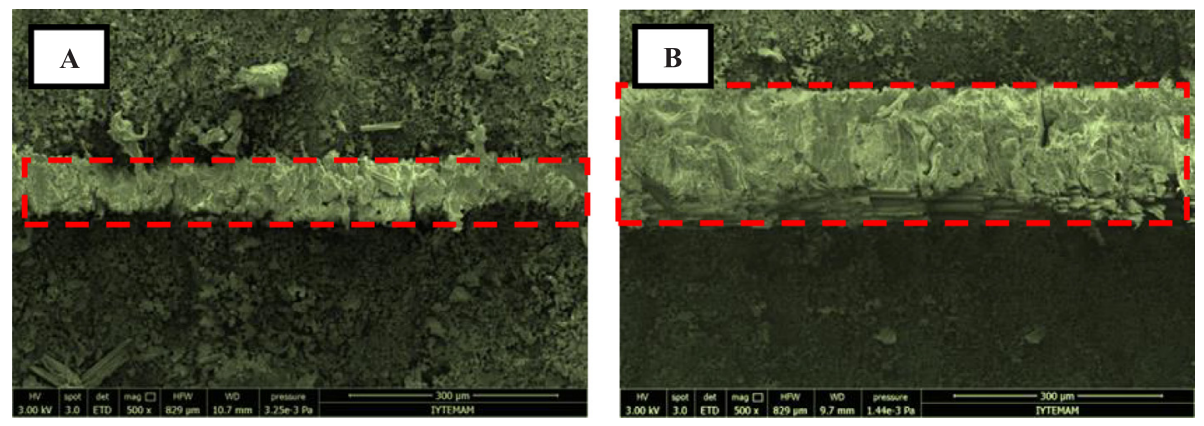

Fig. 4. SEM images of (a) PA66 $17 \mathrm{gsm}$ and (b) PA66 $50 \mathrm{gsm}$ interleaved composite laminates. 


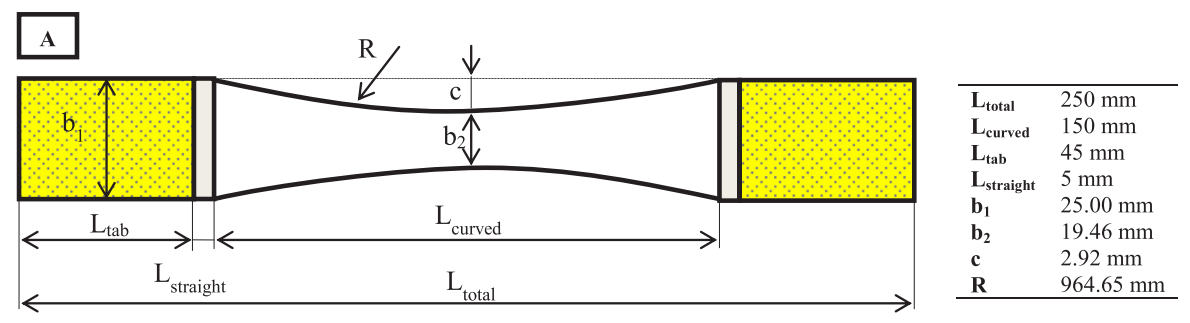

B

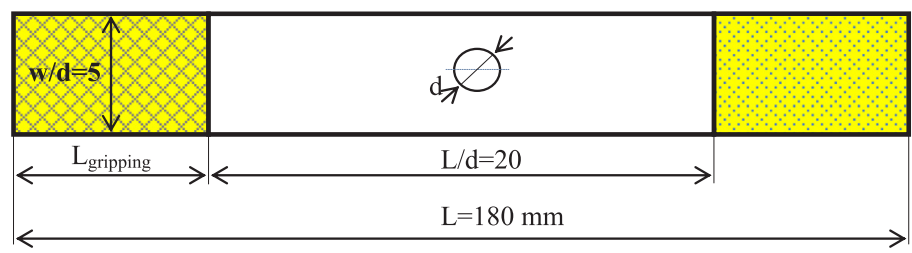

Fig. 5. Geometry of (a) a dumbell-like shape tensile and (b) OHT specimen.
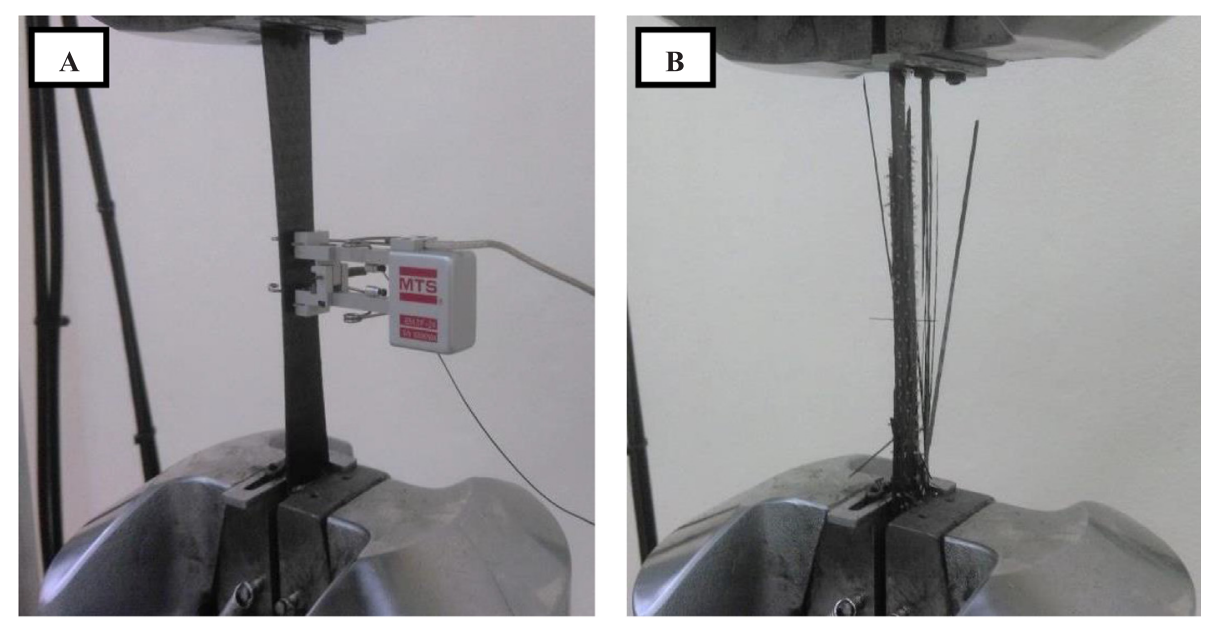

Fig. 6. Photographs of a tensile test specimen (a) before and (b) after tensile testing.

allowed to propagate a short distance $(3-5 \mathrm{~mm})$ before the specimen was unloaded. Then, the specimen was loaded until the crack propagated about 50-60 mm from tip of the crack. Load, opening displacement and crack length were recorded for the energy release rate $\left(G_{I}\right)$ calculation during the tests. $\mathrm{G}_{\mathrm{I}}$ was calculated from Modified Beam Theory data reduction method given as follows [35]:

$G_{I}=\frac{F}{N} \frac{3 P \delta}{2 b(a+|\Delta|)}$

where $\mathrm{G}_{\mathrm{I}}$ is the Mode I interlaminar fracture toughness, $P$ is the applied load, $\delta$ is the load point displacement, b is the specimen width, a is the delamination length (crack length), $\Delta$ is a value that is determined experimentally by generating a least squares plot of the cube root of compliance $\left(\mathrm{C}^{1 / 3}\right)$ as a function of delamination length. $F$ and $N$ are the correction parameters to take into account large displacement and the stiffening of the specimens by loading blocks, respectively. These correction factors can be calculated by using the following equations [36];

$F=1-\left(\frac{3}{10}\right)\left(\frac{\delta}{a}\right)^{2}-\left(\frac{3}{2}\right)\left(\frac{\delta t}{a^{2}}\right)$

$N=1-\left(\frac{L^{\prime}}{a}\right)^{3}-\left(\frac{9}{8}\right)\left[1-\left(\frac{L^{\prime}}{a}\right)^{2}\right]\left(\frac{\delta t}{a^{2}}\right)-\frac{9}{35}\left(\frac{\delta}{a}\right)^{2}$

where $t$ and $L^{\prime}$ were shown in Fig. 8. The $\mathrm{G}_{\mathrm{IC}}$ initiation $\left(\mathrm{G}_{\mathrm{Ic}}\right.$, ini $)$ value was determined as the value of $\mathrm{G}_{\mathrm{IC}}$ at which the delamination was visually observed on the edge of the specimen. $\mathrm{G}_{\mathrm{IC}}$ propagation ( $\mathrm{G}_{\mathrm{Ic}, \text { prop }}$ ) value was calculated as the average of the values of $\mathrm{G}_{\text {IC }}$ during crack propagation.

\subsection{Scanning electron microscopy and dynamic mechanical analysis}

Scanning electron microscopy (SEM) observations were made to determine nanofiber morphology and to better understand the toughening mechanisms in the interleaved composites. The specimens were sputter-coated with gold for $90 \mathrm{~s}$ and examined under a Philips XL 30S FEG scanning electron microscope. Dynamic mechanical analysis (DMA) was carried out on the reference and PA 66 interleaved specimens by using a DMA Q800 (TA Instruments, USA) equipment in a dual cantilever mode. The dimensions of the specimens were $65 \mathrm{~mm}$ in length and $10 \mathrm{~mm}$ in width. At least three specimens were tested for each laminate. The heating rate was $2{ }^{\circ} \mathrm{C} / \mathrm{min}$ from room temperature to $150^{\circ} \mathrm{C}$ and the frequency was $1 \mathrm{~Hz}$. In accordance with the ASTM D4065-12 [37], the glass transition temperature $\left(\mathrm{T}_{\mathrm{g}}\right)$ of the reference and PA 66 interleaved composite specimens were defined by determining the temperature at the peak maximum of the $\tan \delta$ vs. temperature curve.

\section{Results and discussion}

Fig. 9 shows representative stress-strain curves of the reference and PA 66 interleaved CF/EP composites. The stress-strain behavior of the specimens was linear at the initial stage of loading. After some 


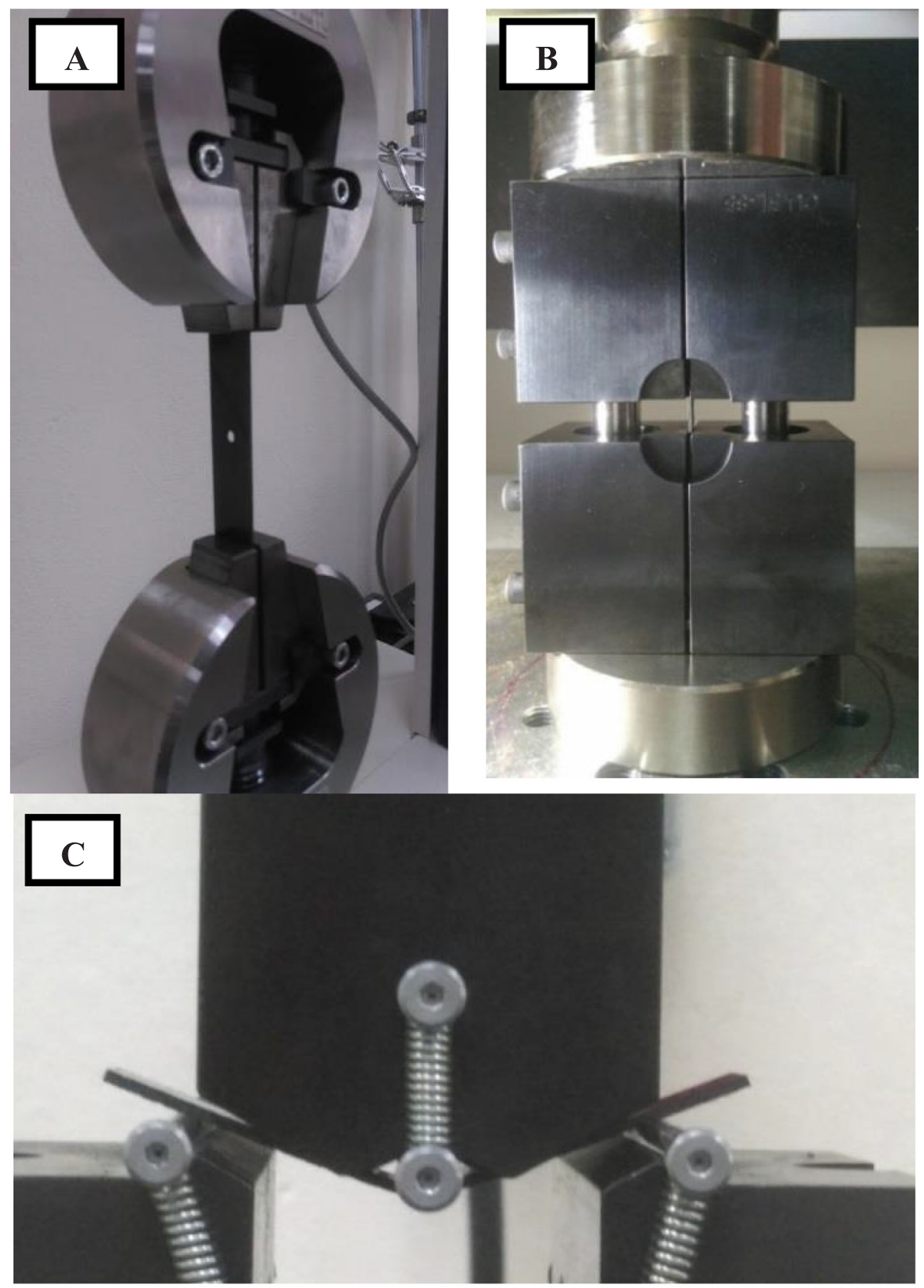

Fig. 7. Photographs of the test specimens under (a) tensile, (b) compression and (c) flexural loading.
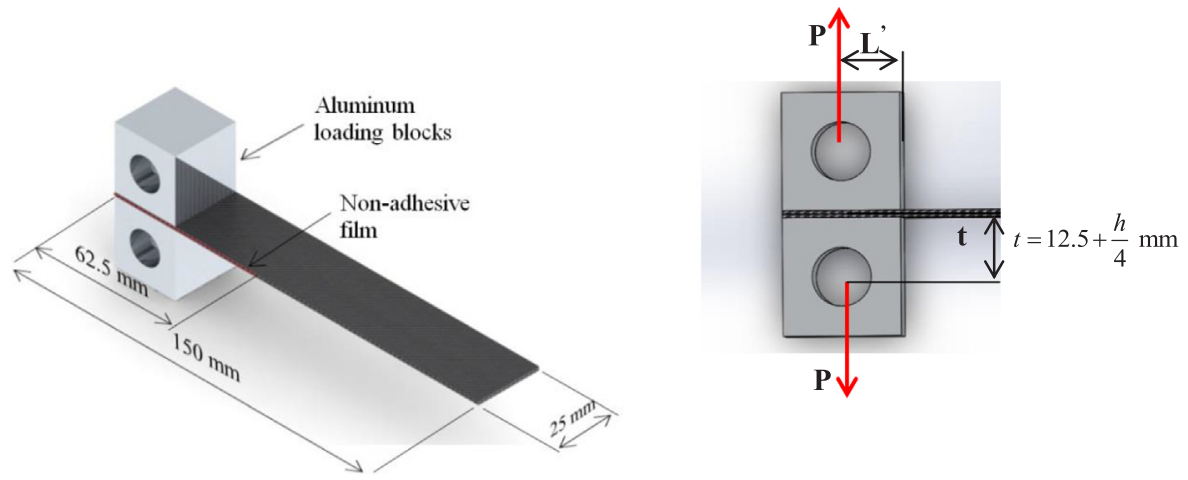

Fig. 8. Schematic representation of the DCB test specimens. 


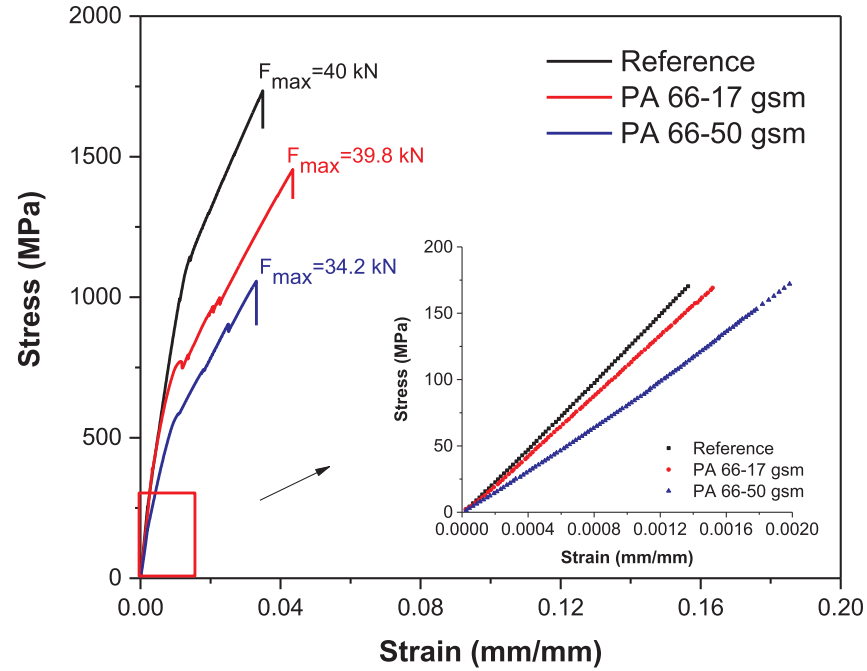

Fig. 9. Representative stress-strain curves of the CF/EP composites.

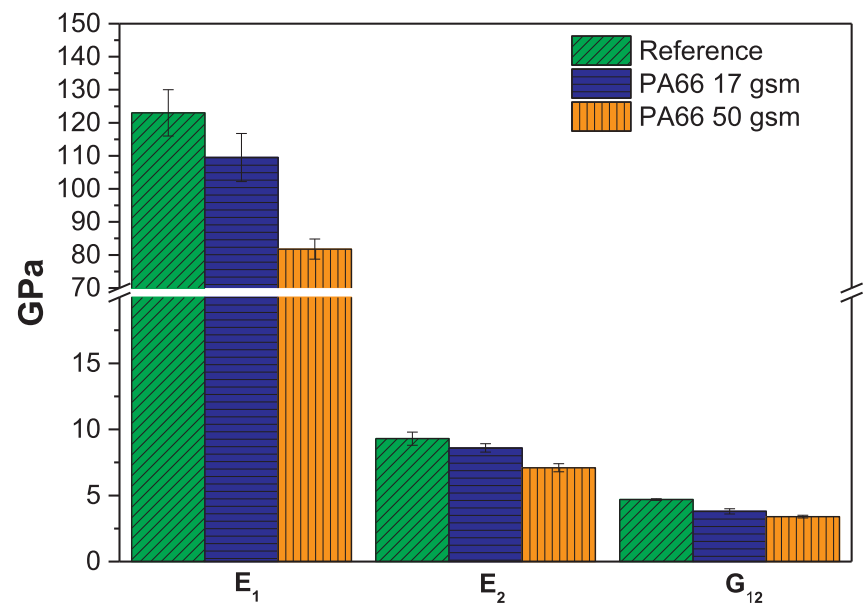

Fig. 10. Longitudinal $\left(E_{1}\right)$, transverse $\left(E_{2}\right)$ and shear modulus $\left(G_{12}\right)$ of the composite specimens.

displacement, the slope of stress-strain curve decreased due to transverse matrix cracking and fiber/matrix debonding which causes laminate stiffness loss. In the reference specimens, the load values increased up to $40 \mathrm{kN}$ followed by a catastrophic failure generating a loud noise and a sudden load drop. PA 66-17 gsm interleaved specimens failed at approximately the same failure load however the stress values were lower than those of reference specimens due to the lower stiffness of veil material in the interlaminar region and increased thickness. PA 66$50 \mathrm{gsm}$ interleaved composites experienced final failure at lower stress and strain values due to the lower carbon fiber content as compared to other specimens. Fig. 10 shows the tensile test results for the reference and PA 66 interleaved specimens. In the longitudinal direction, the elastic modulus $\left(\mathrm{E}_{1}\right)$ and tensile strength $\left(\sigma_{\mathrm{x}}\right)$ of the reference composites were determined as $123.0 \mathrm{GPa}$ and $1786.3 \mathrm{MPa}$, respectively. Incorporating $17 \mathrm{gsm}$ of PA 66 veil into the interlaminar region reduced fiber volume fraction from 55 to $46 \%$, and hence, the elastic modulus and tensile strength of the composites reduced by 10.97 and $19.70 \%$ respectively. The addition of denser PA $66-50 \mathrm{gsm}$ in the interlaminar region led to higher reduction in the carbon fiber volume fraction and increased the thickness of the composites. Therefore, the elastic modulus and tensile strength of PA 66-50 gsm interleaved specimens were 33.59 and $41.26 \%$ lower than those of the reference specimens. In the transverse direction, the elastic modulus $\left(\mathrm{E}_{2}\right)$ and tensile strength $\left(\sigma_{\mathrm{y}}\right)$ of the reference composites were determined as $9.3 \mathrm{GPa}$ and 36.09 MPa, respectively. The addition of PA 66 veils caused reductions in the elastic modulus of the composites. However, the tensile strength in the transverse direction was not seem to be negatively affected by the addition of PA 66 veils. The tensile strength of all composites was in the range between 35 and $36 \mathrm{MPa}$. The tensile strength in the transverse direction is a matrix-dominated property. Therefore, it can be said that the PA 66 veils retained the matrix properties of the composites. The tensile properties, except the tensile strength in the transverse direction, showed a decreasing tendency with the incorporation of PA 66 veils. Table 2 shows the tensile properties of the composite specimens. Another important observation during the tensile tests was that while the reference specimens failed in a catastrophic brittle manner (Fig. 6b), the incorporation of PA 66 veils in the interlaminar region altered the mode of failure from catastrophic to noncatastrophic as shown in Fig. 11. The plastic deformation of the PA66 fibers in the matrix reduces the stress concentration between the adjacent carbon plies and also reduces risk of catastrophic failure across the carbon plies. The shear modulus $\left(G_{12}\right)$ of the reference specimens were calculated as $4.3 \mathrm{GPa}$ using Eq. (1). The addition of PA 66-17 and PA 66$50 \mathrm{gsm}$ veils reduced the shear modulus of the composites about $14 \%$ and $21 \%$, respectively.

Fig. 12 shows the representative force-displacement curves of the OHT specimens. The applied load increased almost linearly followed by a mostly nonlinear portion. After some displacement, the failure occured until the force reached to a maximum value. In the longitudinal direction, the failure loads of the interleaved specimens were higher than those of reference specimens. The displacement value was also higher than the reference specimens. In all specimens, the observed failure mode was longitudinal splitting grew from the grip to grip at the early stage of failure shown in Fig. 13(a). This failure mode generally occurs in the unidirectional fiber reinforced composites. However, it is not one of the acceptable failure modes for OHT tests in the ASTM standard. Therefore, in this study, only the OHT values in the transverse direction were reported. Fig. 13(b) shows one of the acceptable failure modes observed in the transverse direction. Laminate tensile failure occured laterally across the center of the hole in these specimens. The OHT values were calculated as $31.59 \pm 2.85,30.87 \pm 0.88$ and

Table 2

Tensile and flexural test results of the CF/EP composites with/without PA 66 veils.

\begin{tabular}{|c|c|c|c|c|}
\hline & Mechanical property & Reference & $\begin{array}{l}\text { PA } 6617 \mathrm{gsm} \\
\text { interleaved specimens }\end{array}$ & $\begin{array}{l}\text { PA } 6650 \mathrm{gsm} \\
\text { interleaved specimens }\end{array}$ \\
\hline \multirow[t]{5}{*}{$\mathrm{LD}^{*}$} & $E_{1}$, Elastic modulus (GPa) & $123.0 \pm 7.00$ & $109.5 \pm 7.29$ & $81.78 \pm 3.03$ \\
\hline & Tensile strength (Mpa) & $1786.34 \pm 72.0$ & $1434.35 \pm 35.3$ & $1049.3 \pm 10.9$ \\
\hline & Flexural strength (Mpa) & $1281.41 \pm 90.9$ & $1119.60 \pm 84.72$ & $972.62 \pm 40.38$ \\
\hline & Flexural modulus (Gpa) & $104.69 \pm 5.9$ & $82.99 \pm 3.95$ & $75.93 \pm 3.12$ \\
\hline & $G_{12}$, Shear modulus (Gpa) & $4.3 \pm 0.06$ & $3.75 \pm 0.2$ & $3.4 \pm 0.1$ \\
\hline \multirow[t]{4}{*}{$\mathrm{TD}^{*}$} & $E_{2}$, Elastic modulus (Gpa) & $9.3 \pm 0.5$ & $8.6 \pm 0.32$ & $7.1 \pm 0.31$ \\
\hline & Tensile strength (Mpa) & $36.09 \pm 4.8$ & $35.57 \pm 1.47$ & $35.21 \pm 1.37$ \\
\hline & Flexural modulus (Gpa) & $6.65 \pm 0.8$ & $6.21 \pm 0.90$ & $5.25 \pm 0.77$ \\
\hline & Flexural strength (Mpa) & $61.10 \pm 6.9$ & $80.36 \pm 5.76$ & $70.06 \pm 5.02$ \\
\hline
\end{tabular}

* LD: longitudinal direction, TD: transverse direction. 


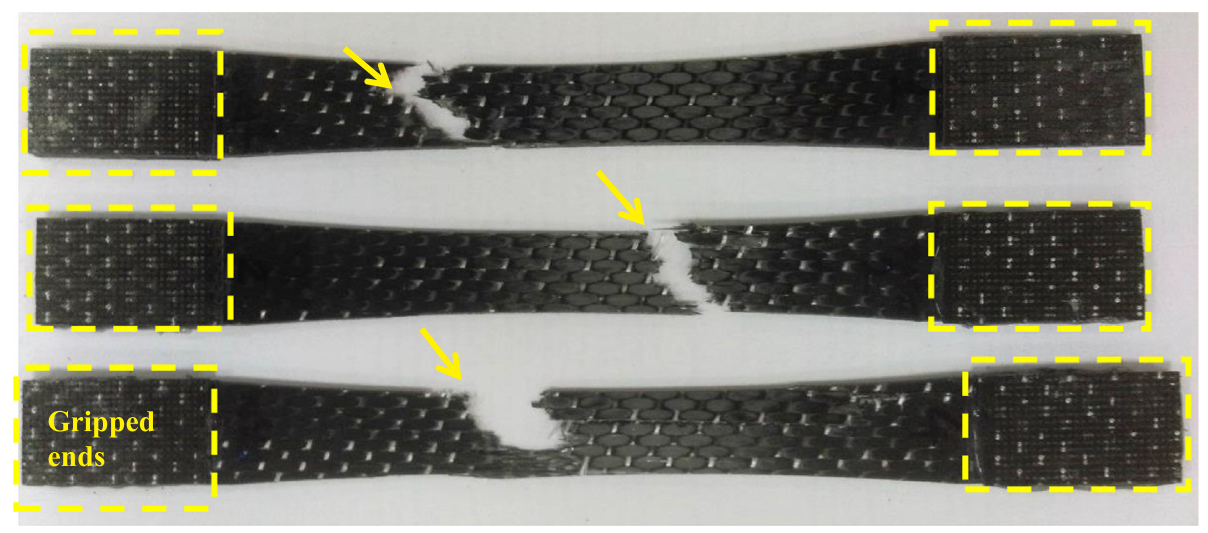

Fig. 11. Failed PA66 nonwoven veil interleaved test specimens.

$33.81 \pm 0.58 \mathrm{MPa}$ for the reference, PA 66-17 and PA 66-50 gsm veils; respectively. Although the PA66 veils caused an increase in thickness which increases the gross cross-sectional area of the specimens, these veils had no negative effect on the OHT strength of the composites. Moreover, a slight increase (about 7\%) was noted in OHT strengths with the addition of PA 66 veils as compared to reference specimens. The veils retains the structural integrity of the specimens by reducing the risk of delamination which led to higher maximum loads as compared to reference specimens. It can be also said that the specimens interleaved with PA 66 veils exhibited more uniform failure considering the reduced standard deviations of test data.

The flexural modulus and strength values of the composite specimens were also given in Table 2. In the longitudinal direction, the flexural strength and the flexural modulus of the reference specimens were $1281.4 \mathrm{MPa}$ and 104.7 GPa, respectively. Incorporating $17 \mathrm{gsm}$ of PA 66 veil into the interlaminar region increased the thickness of the specimen to $1.46 \mathrm{~mm}$ and reduced the carbon fiber volume fraction from 0.55 to 0.46 . As a result, the flexural strength and flexural modulus decreased to $1119.6 \mathrm{MPa}$ and $82.9 \mathrm{GPa}$, which were $12.62 \%$ and $20.8 \%$ lower than those of the reference specimens. Increasing the areal density of the interleaf material from $17 \mathrm{gsm}$ to $50 \mathrm{gsm}$ caused higher reduction in flexural strength and modulus by 24.1 and $27.5 \%$ respectively, as compared to reference specimens due to the increased thickness, lower carbon fiber volume fraction and lower stiffness of interleaf material surrounding the carbon fibers. It is known that the flexural strength in longitudinal direction is a fiber-dominated property while transverse flexural strength is an important parameter to assess the interfacial bonding between the reinforcement and the polymer matrix. In the transverse direction, the flexural strength and the flexural modulus of the reference specimens were $61.10 \mathrm{MPa}$ and $7.26 \mathrm{GPa}$,

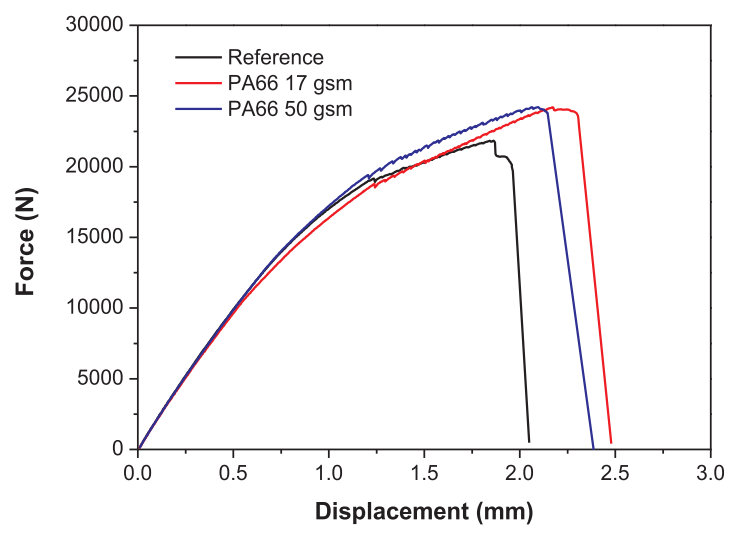

(a)
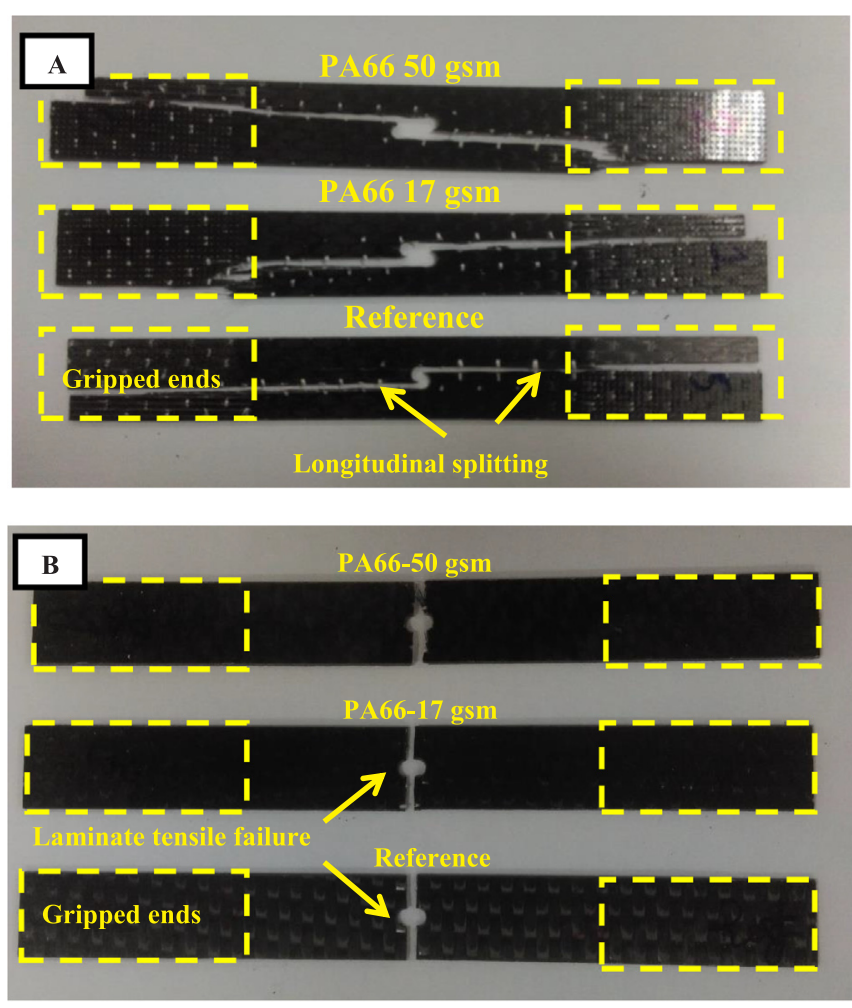

Fig. 13. Observed failure modes in OHT tests (a) Longitudinal splitting and (b) tensile failure.

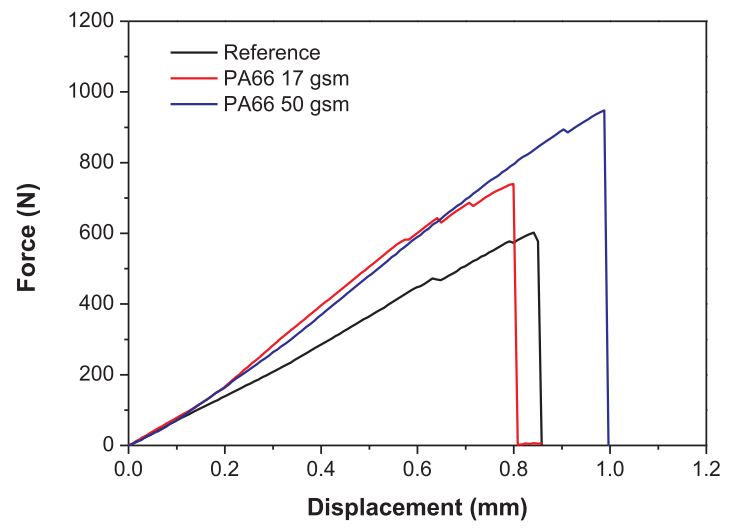

(b)

Fig. 12. Representative load-displacement curves of the OHT specimens (a) Longitudinal and (b) transverse direction. 


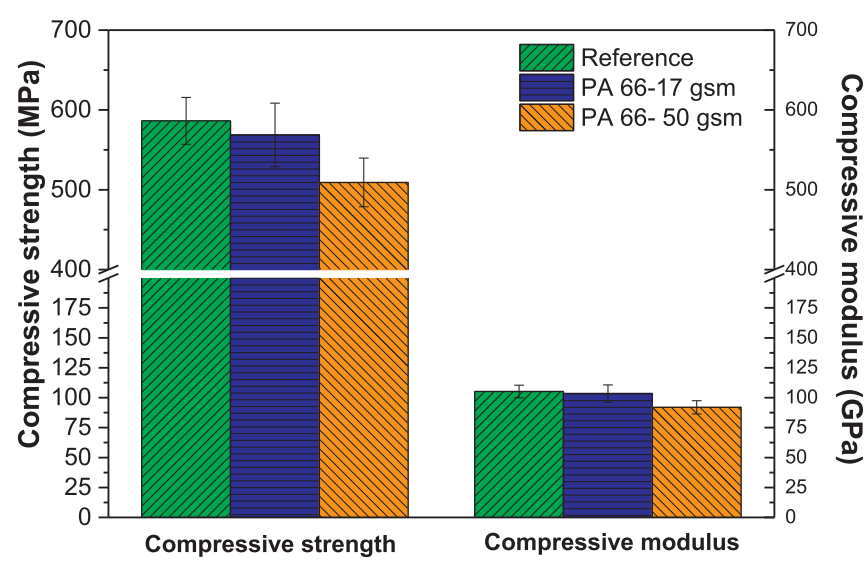

Fig. 14. Compressive test results of the CF/EP composites.

respectively. The addition of $17 \mathrm{gsm}$ of PA 66 veil led to a significant increase in flexural strength of the composite of about $31 \%$. The PA 66$50 \mathrm{gsm}$ veils also improved the flexural strength of about $14.7 \%$ as compared to reference specimens. Therefore, it can be concluded that the PA66 veils improved fiber/matrix interfacial adhesion significantly resulting in better bending performance. The flexural modulus of the composites was found to be reduced from 6.65 to $6.21 \mathrm{GPa}$, from 6.65 to $5.25 \mathrm{GPa}$ for the PA66 $17 \mathrm{gsm}$ and PA $6650 \mathrm{gsm}$ veils, respectively. These correspond to a 6.76 and a $21.1 \%$ decrease for the PA $66-17$ and PA 66-50 gsm veils, respectively. The reduction in transverse flexural modulus caused by PA 66 nonwovens was much smaller than those of observed in the longitudinal direction.

Fig. 14 shows the compression test results of the CF/EP composites. The compressive modulus and strength of the reference specimens were determined as $105.19 \mathrm{GPa}$ and $586.4 \mathrm{MPa}$ respectively. It was observed that the compressive strength and modulus decreased with the inclusion of PA 66-17 gsm veils. Although increasing veil density reduced compressive strength and modulus as in the case of tensile properties, a moderate reduction about $13 \%$ was observed in both values due to the PA 66 veils. Unlike tensile properties which are fiber dominated, compressive properties depends on many factors such as matrix modulus and strength, fiber/matrix interfacial bond strength. Therefore, it can be said that these veils improves the interfacial bond strength of the composites.

Fig. 15 shows the Charpy-impact and interlaminar shear strength test results of the CF/EP composites. The impact fracture energy of the reference specimens was measured to be $106.28 \pm 17.30 \mathrm{~kJ} / \mathrm{m}^{2}$. The

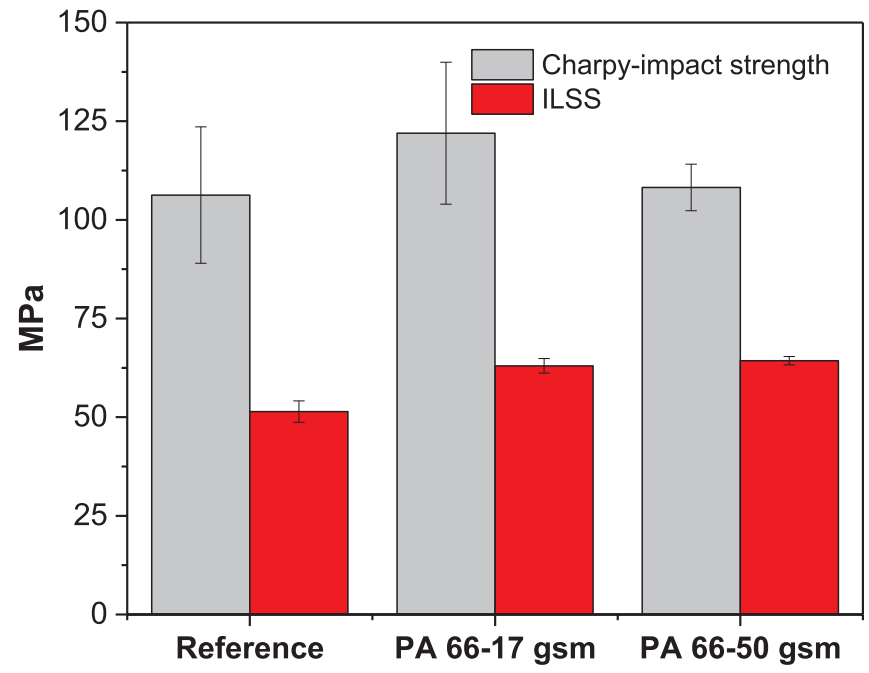

Fig. 15. Charpy-impact and ILSS test results of the CF/EP composites. impact fracture energy increased about $15 \%\left(121.96 \pm 18 \mathrm{~kJ} / \mathrm{m}^{2}\right)$ by introducing PA 66-17 gsm veils on the interface area of composite laminates. Although the addition of denser PA $66-50 \mathrm{gsm}$ veils led to higher impact energies, the thickness of the specimens increased about $37.9 \%$ therefore the impact strength of the composites almost remained unchanged at $108.21 \pm 5.9 \mathrm{~kJ} / \mathrm{m}^{2}$ compared to reference specimens. The improved impact energy can be explained by analyzing the SEM images of the fracture surfaces of reference and PA 66 interleaved specimens. As seen in Fig. 16(a), reference specimens had a glassy and smooth fractured surface and showed no sign of plastic deformation (brittle fracture). These are main characteristics of poor interfacial bonding strength and impact energy. However, as seen in Fig. 16(b-d), PA 66 interleaved specimens exhibited more complex fractured surface which indicates higher matrix deformation and absorbed impact energy. At the moment of impact, the whole area of PA 66 interleaves involved in resisting to the applied load and improved the load-bearing capacity of the composites. The fracture around the PA66 fiber in Fig. 16(c-d) shows the load absorbed by the veil fiber and distributed to the surrounding matrix. The imprints of broken and torn PA 66 fibers can be seen in Fig. 16(d).

The ILSS is one of the most significant mechanical property for determining the ability of a laminated composite to resist delamination damage. Due to higher interlaminar shear stress, delamination may occur in the composite interface. The ILSS of the reference specimens was determined as $51.43 \pm 2.72 \mathrm{MPa}$. On the other hand, the ILSS of the PA 66-17 and PA 66-50 gsm interleaved specimens were determined as $63.01 \pm 1.86 \mathrm{MPa}$ and $64.32 \pm 1.07 \mathrm{MPa}$ respectively. It was observed that the incorporation of PA 66-50 gsm veils led to a significant increase of about $25.1 \%$. The improved shear performance may be related to hydrogen bonding between the amide groups of nylon and the ether groups of epoxy resin. This good chemical bonding improves the wetting efficiency and gives a resin-rich surface which possibly arrests the crack initiation at the interface of the composites. Also, the polymer matrix containing PA 66 fibers led to a more uniform distribution of shear stresses in the interlaminar region and transmitted the load to the carbon plies resulting in higher shear strength with a lower standard deviation.

Fig. 17 shows the representative load-displacement curves of the composite specimens under Mode-I loading. The dots shows the first visible crack observed on the edge of the specimens. The maximum load $\left(F_{\max }\right)$ values were determined as $11.83 \pm 1.43 \mathrm{~N}, 23.61 \pm 4.21 \mathrm{~N}$ and $48.2 \pm 6.85 \mathrm{~N}$ and for the reference, and PA 66 interleaved composites with $17 \mathrm{gsm}$ and $50 \mathrm{gsm}$ veil density, respectively. It was observed that the maximum force increased about $99.6 \%$ and $307 \%$ for PA 66-17 and PA 66-50 gsm interleaved specimens respectively as compared to reference specimens. The load-displacement curves of the reference specimens were jag-shaped which was one of the main characteristics of unidirectional fiber reinforced composites under Mode-I loading. The jagged load-displacement response is a sign of unstable crack propagation. Until the failure of the specimen, the crack continued to propagate with every sudden load drop as can be seen in Fig. 17. The displacement values were determined as $120.97 \pm 2.52 \mathrm{~mm}, 131.14 \pm 6.65 \mathrm{~mm}$ and $139.90 \pm 4.51 \mathrm{~mm}$ for the reference, and PA 66 interleaved composites with $17 \mathrm{gsm}$ and $50 \mathrm{gsm}$ veil density, respectively. The displacement values of PA66 interleaved specimens were significantly higher than those of the reference specimens. Based on observations made during DCB testing, the crack in the PA 66 interleaved specimens traveled much more slowly until full separation of the plates and therefore the load decreased more gradually than the reference specimens. It was also note-worthy that PA 66-50 gsm veils changed the response of the composite from jag-shaped to bow-shaped which is generally observed in woven composites. The bow-shaped response, or smoother descending response, indicated that the crack propagation in the interleaved specimens was quite slow, stable and gradual compared with the reference composite specimens.

Fig. 18 represents least squares plots of the cube root of compliance 

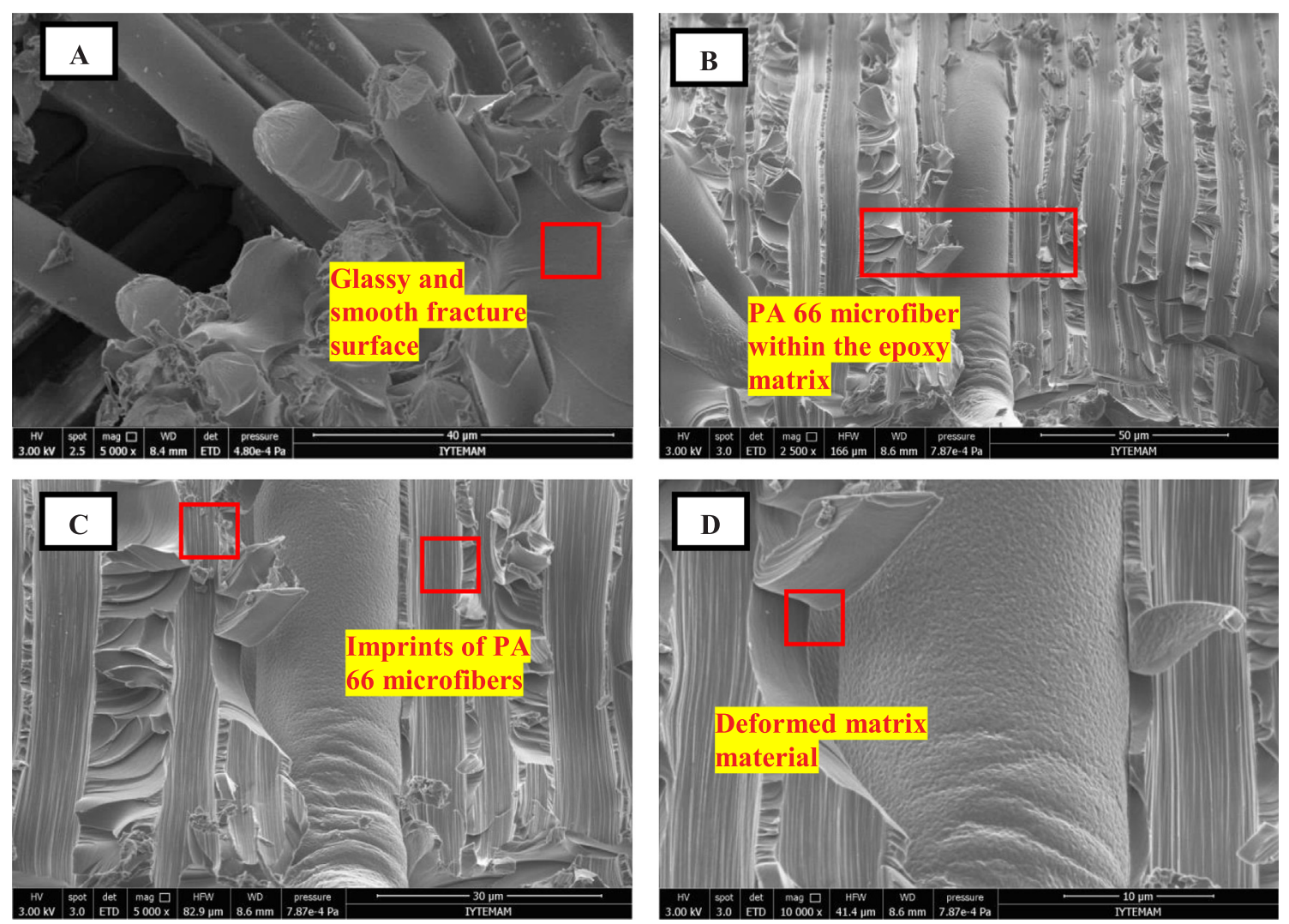

Fig. 16. SEM images of fractured surfaces of (a) reference and (b-d) PA66 interleaved specimens after impact.

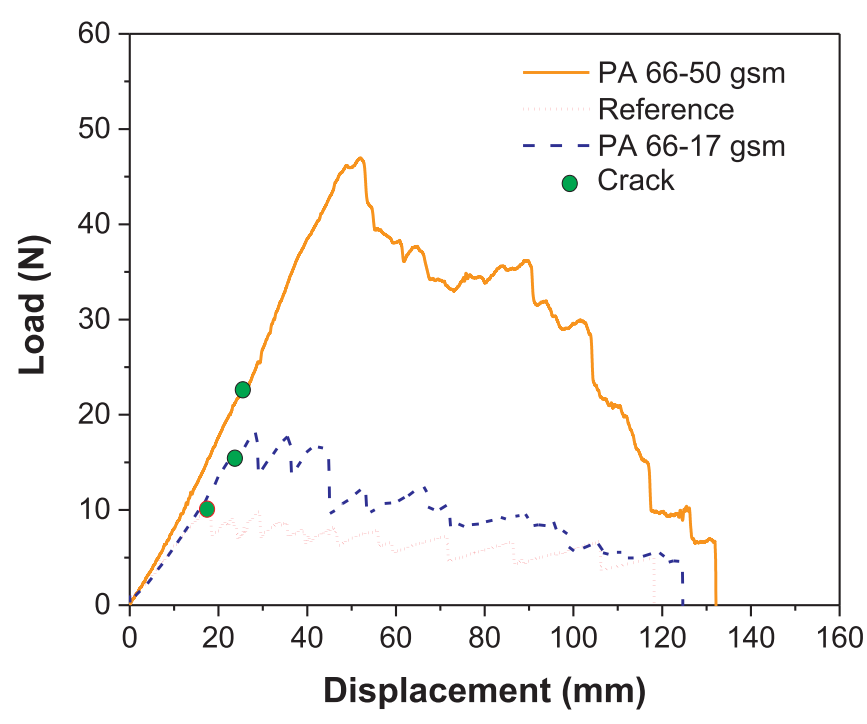

Fig. 17. Representative load-displacement curves of the DCB specimens.

$\left(C^{1 / 3}\right)$ as a function of delamination length for the reference, PA 6617 gsm and PA 66-50 gsm interleaved CF/EP composites. Fig. 19 shows the R-curves of the reference and PA 66 interleaved composite specimens. The calculated Mode-I fracture toughness using Eq. (2) was in the range between 0.180 and $0.332 \mathrm{~kJ} / \mathrm{m}^{2}$ for the reference specimens while the Mode-I fracture toughness of the PA $66-17 \mathrm{gsm}$ interleaved specimens was in the between 0.340 and $1.102 \mathrm{~kJ} / \mathrm{m}^{2}$. Increasing veil density from $17 \mathrm{gsm}$ to $50 \mathrm{gsm}$ led to much higher Mode-I fracture toughness values so it reached to its maximum value between 1.173 and $2.780 \mathrm{~kJ} / \mathrm{m}^{2}$. This corresponds to about 231 and $737 \%$ improvement of the Mode-I fracture toughness for PA 66-17 gsm and PA 66-50 gsm interleaved specimens, respectively, as compared to those for reference specimens. This associates with the excessive PA66 fiber bridging mechanism within the interlaminar region which will be discussed in more detail below. The initiation and propagation Mode-I fracture toughness values for the reference specimens were determined as 0.185 and $0.237 \pm 0.061 \mathrm{~kJ} / \mathrm{m}^{2}$; respectively. For the composites interleaved with PA66-17 gsm veils, the initiation and propagation Mode-I fracture toughness values were determined as 0.342 and $0.643 \pm 0.139 \mathrm{~kJ} / \mathrm{m}^{2}$; respectively. This corresponds to about 84 and $171 \%$ improvement of those values, respectively, as compared to those for reference specimens. For the composites containing 50 gsm PA 66 interleaves, the initiation and propagation fracture toughness values were found to be 0.831 and $1.940 \pm 0.384 \mathrm{~kJ} / \mathrm{m}^{2}$ which corresponds to as high as 349 and $718 \%$ improvement as compared to the reference specimens. It was also seen that the standard deviation of the Mode-I fracture toughness of the interleaved specimens was higher than those of reference specimens. In some cases, the crack in the interleaved specimens jumped to the relatively weak fiber/matrix interface and continued to propagate in this region. This resulted in the lower fracture toughness values when the crack propagated almost $1 / 3$ of the total delamination length as can be seen in Fig. 19.

Fig. 20 shows the excessive PA 66 fiber bridging observed during the DCB tests. Due to the good adherence between epoxy and PA 66 veils, PA 66 veils absorbed high amount of strain energy by bridging the crack opening and tearing which contribute to the improvement of delamination resistance. The SEM fracture surface images of the Mode-I specimens with/without PA66 veils are shown in Fig. 21. The micrographs were taken from the middle of the specimens (away from the initial crack region) for interpreting fracture mechanisms. As seen in Fig. 21(a), the reference specimens exhibits smooth and featureless (indicating more brittle) failure characteristics of the composites under Mode-I loading. Mode-I fracture toughness is controlled by processes such as cohesive fracture of the matrix and fiber bridging as stated by Greenhalgh et al. $[1,2]$. Debonding of the carbon fibers from the epoxy matrix is visible in Fig. 21(b). On the other hand, PA 66 interleaved 


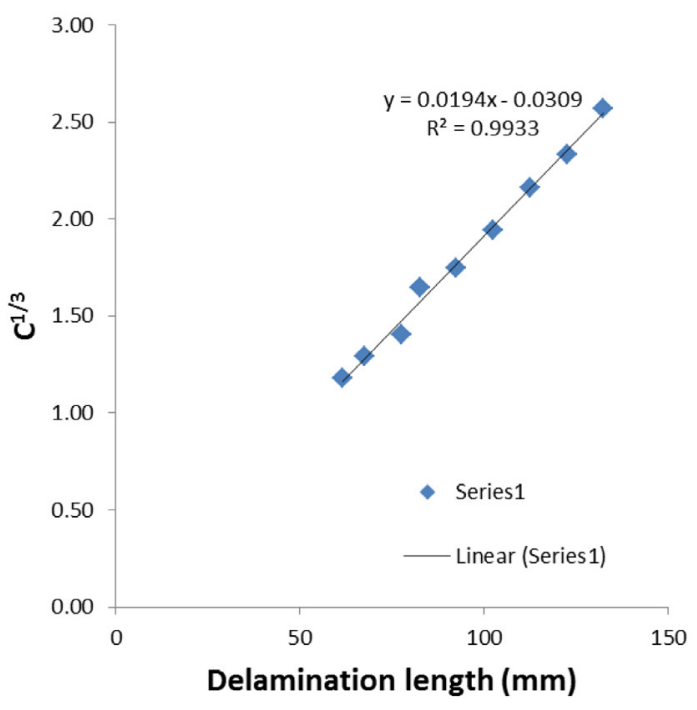

(a)

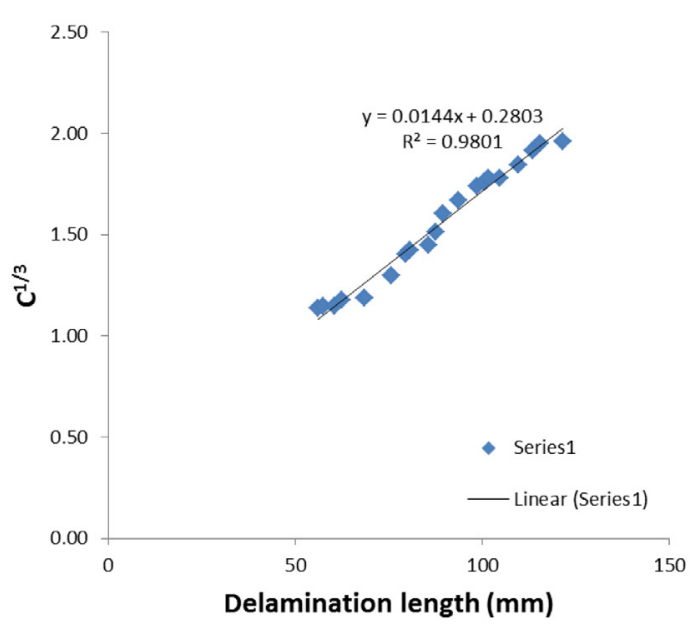

(b)

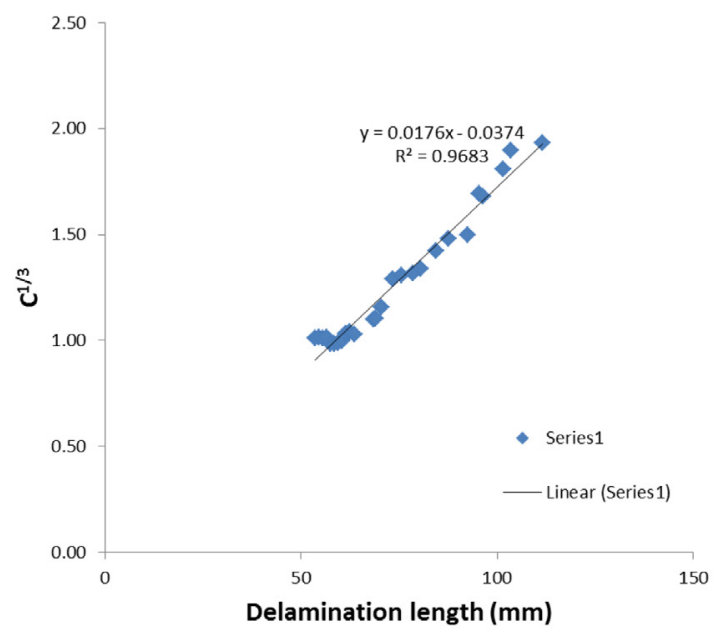

(c)

$1 / 3$

Fig. 18. Least squares plot of the cube root of compliance, $C^{1 / 3}$ as a function of delamination length (a) reference, (b) PA 66-17 gsm and (c) PA 66-50 gsm composites.

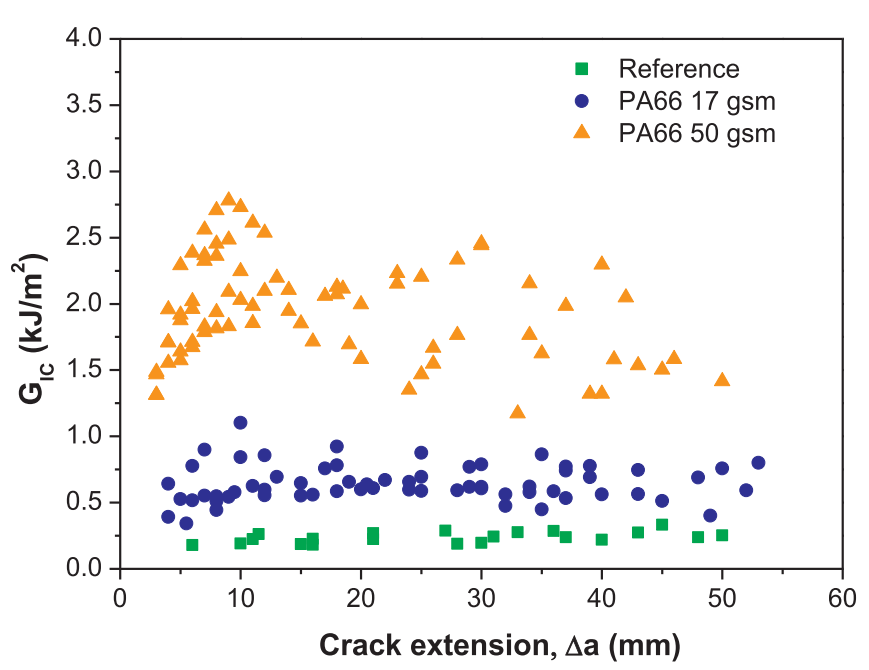

Fig. 19. R-curves of the reference and PA66 interleaved composite specimens.

specimens exhibit a different type of failure surface as seen in Fig. 21(c-d). A high amount of torn PA 66 fibers and minimal matrix fracture was observed in the interleaved specimens. Also, the pulled-out PA 66 fibers from the matrix and the imprints of PA 66 fibers on the other side of the delamination plane can be seen in these figures. The SEM images and the observation during the DCB tests revealed that the main toughening mechanism was the PA 66 fiber bridging which led to much higher interlaminar fracture toughness and more stable crack propagation in the interleaved specimens.

Fig. 22 shows DMA test results of the reference and PA 66 interleaved specimens in both longitudinal and transverse directions. The average values of storage modulus, loss modulus, $\tan \delta, \tan \delta$ (peak) and glass transition temperature $\left(\mathrm{T}_{\mathrm{g}}\right)$ of specimens were also reported in this figure. Fig. 22(a and b) represents the effects of PA 66 interleaf material on the storage and loss modulus of the specimens at room temperature $\left(25^{\circ} \mathrm{C}\right)$. The storage modulus is the elastic response of the material and the loss modulus measures the energy dissipated as heat. The results showed that both storage and loss modulus decreased with the incorporation of PA 66 veils in the longitudinal direction. The interleaf material gives more flexibility resulting in the low stiffness and low storage modulus. The decrease in storage modulus was about 26.4 and $31.2 \%$ for PA66-17 and PA 66-50 gsm veils, respectively. These results were consistent with the results of three-point bending test results. The loss modulus of the composites also exhibited a decline with the addition of PA 66 veils. More slight decrease in the loss modulus of the composites was observed so that the loss modulus decreased about 25.3 and $21.7 \%$ for PA $66-17$ and PA $66-50$ gsm veils, respectively. In the transverse direction, the storage modulus of the specimens was not significantly affected by the addition of PA 66 veils. It was also observed that the loss modulus increased about 20.1 and 50.4\% for PA 66 $17 \mathrm{gsm}$ and PA 65-50 gsm veils, respectively. A small rise in $\tan \delta$ and $\tan \delta$ (peak) was observed which is a positive effect of adding PA66 veils to the interlaminar region (Fig. 22c-d). It can be concluded that the damping ability of the composites improved with the addition of PA 66 veils on the interlaminar region of composites. In Fig. 22(d), the glass transition temperature $\left(\mathrm{T}_{\mathrm{g}}\right)$ of the specimens were also reported. The $\mathrm{T}_{\mathrm{g}}$ of reference, PA 66-17 and PA 66-50 gsm interleaved composite specimens was determined as $85.45,86.37$, and $86.16^{\circ} \mathrm{C}$, respectively. The PA 66 interleaving had no significant effect on the $\mathrm{T}_{g}$ of composite specimens. The good chemical interaction between the PA 66 fibers and epoxy resin retained the $T_{g}$ of the composites. The DMA results indicates that although the veils caused a decrease in the storage modulus of the specimens, the transition temperature of the composites was not affected due to the presence of PA 66 veils.

A comparison of PA 66 and other various systems reported in the 

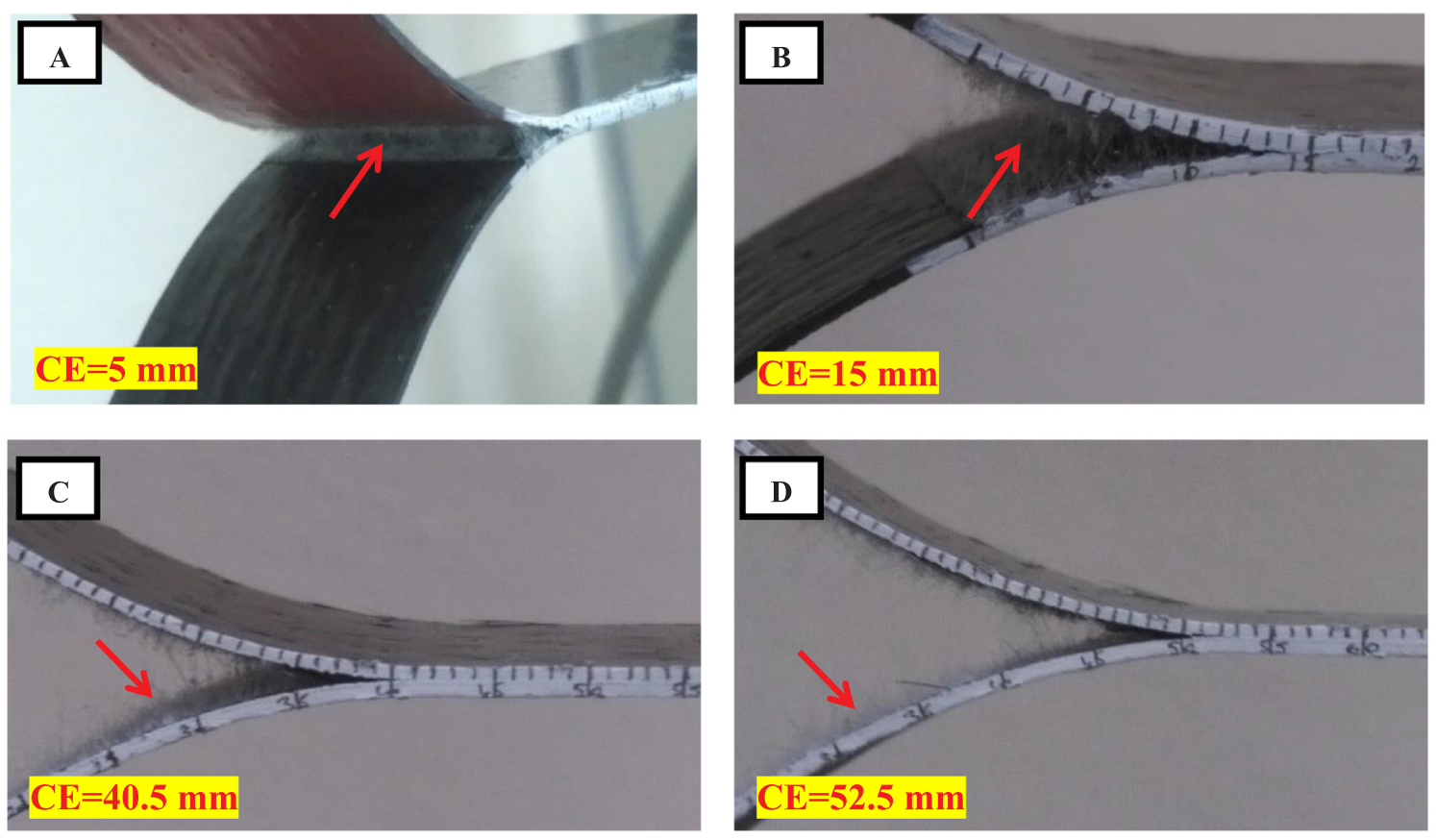

Fig. 20. Photographs of PA66 fiber failure (CE: crack extension).

literature is shown in Table 3. It is obvious that the PA is the most effective interleaf material in terms of Mode-I fracture toughness. The selection of nonwoven material is also critical to obtain desired mechanical properties. Although carbon fibers are much stronger than PA fibers, most of these fibers are not pulled out from the matrix in the composites (no significant fiber bridging) during the loading.
Therefore, the increase in Mode-I fracture toughness values was much lower than the PA 66 interleaved composites. As can be seen in Table 3, increasing veil density results in higher Mode-I fracture toughness. This is due to the fact that higher amount of veil fibers provide a higher extent of fiber bridging that occurred behind the crack fronts and contributed to the interlaminar fracture toughness. On the contrary,
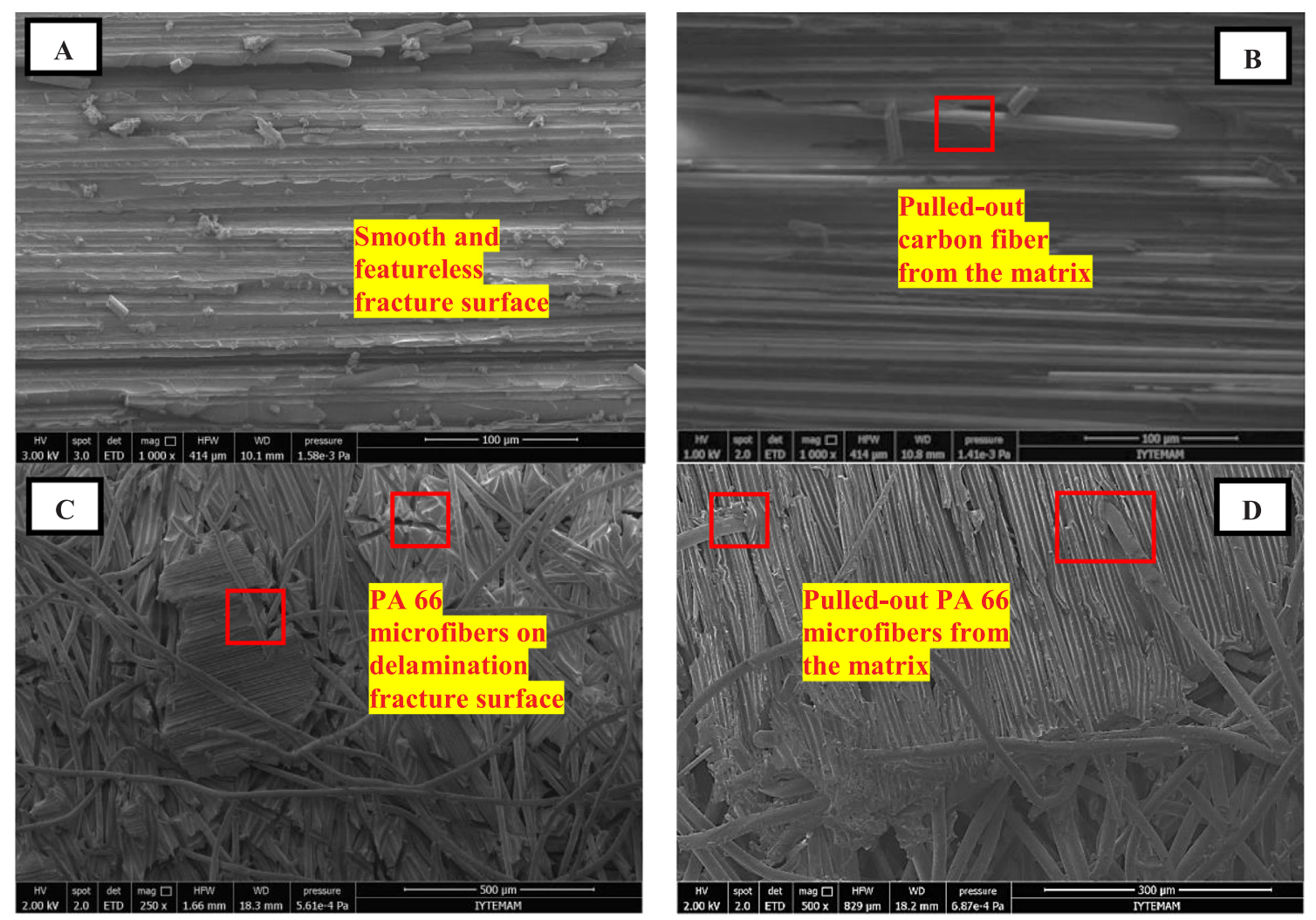

Fig. 21. SEM of DCB test specimen fracture surfaces; (a, b) reference and (c-d) PA 66 interleaved specimens. 


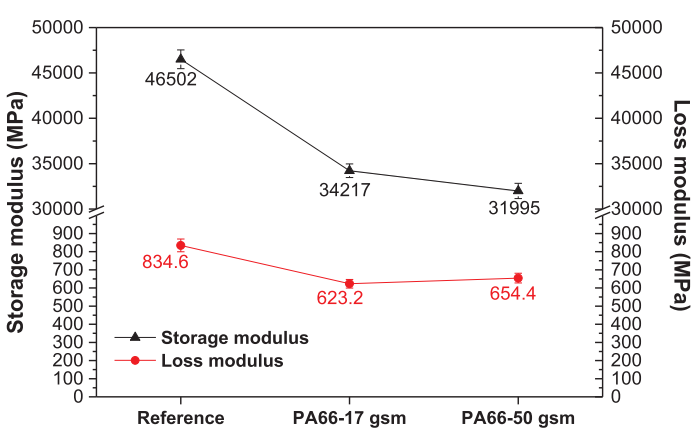

(a)

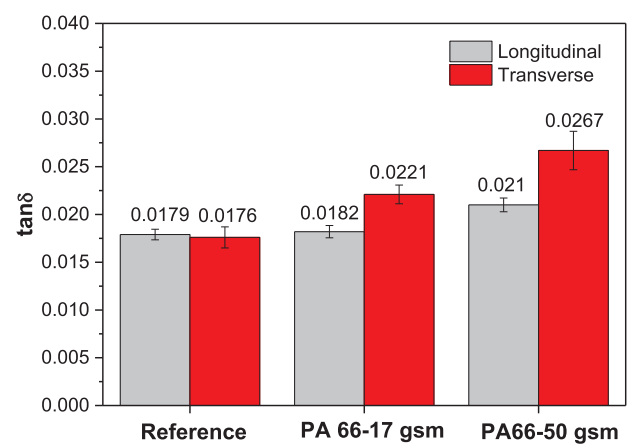

(c)

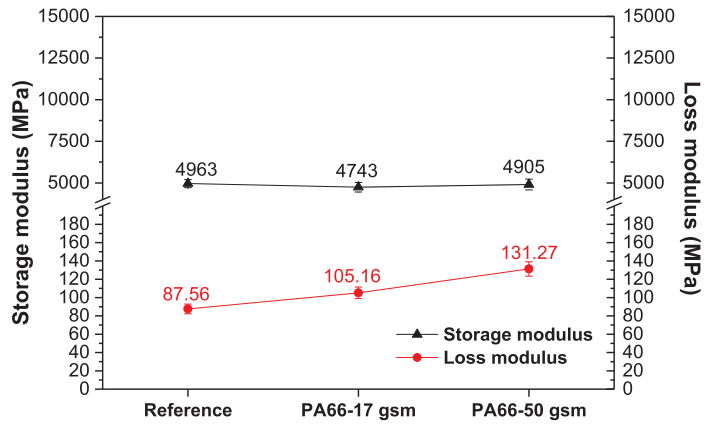

(b)

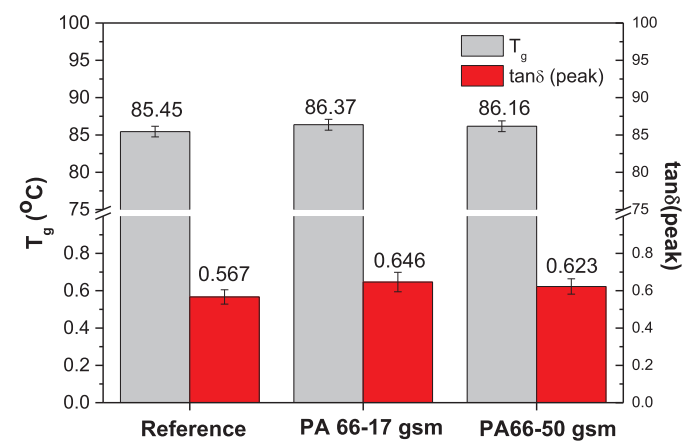

(d)

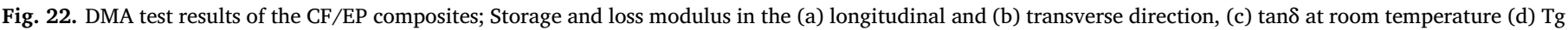
and $\tan \delta$ (peak) values.

Table 3

Comparison of the effectiveness of various microfiber interleaving systems.

\begin{tabular}{lllll}
\hline Reference & $\begin{array}{l}\text { Composite } \\
\text { system }\end{array}$ & $\begin{array}{l}\text { Interleaf } \\
\text { material }\end{array}$ & $\begin{array}{l}\text { Areal weight } \\
\text { density } \\
\left(\mathrm{g} / \mathrm{m}^{2}\right)\end{array}$ & $\begin{array}{l}\text { Mode-I fracture } \\
\text { toughness } \\
(\% \text { increase })\end{array}$ \\
\hline This study & CF/EP & PA & 17 & 171 \\
{$[3]$} & CF/EP & PEEK & 11 & 718 \\
{$[17]$} & CF/EP & PE & 20 & 102 \\
{$[18]$} & GF/VE & PA & 17 & 83 \\
{$[19]$} & GF/VE & PET & 45 & 90 \\
{$[21]$} & GF/PE & PA & 17 & 12 \\
{$[22]$} & GF/PE & PU & 15 & 170 \\
{$[36]$} & CF/EP & CF & 12 & 40 \\
{$[38]$} & CF/EP & PPS & 40 & 13 \\
{$[39]$} & CF/ BZ & PA & 34 & 352 \\
\hline
\end{tabular}

\footnotetext{
1 PEEK: Polyether ether ketone.

2 PPS: Polyphenylene sulphide, BMI: bismaleimide.

3 Benzoxazine.
}

Armstrong-Carroll and Cochran [40] showed that there was an inverse relationship between Mode-II fracture toughness improvement and the areal veil density. A thinner carbon nonwoven mats $\left(6.8 \mathrm{~g} / \mathrm{m}^{2}\right)$ which they included in the laminate lay-ups, led to a higher increase in ModeII fracture toughness as compared to $12 \mathrm{~g} / \mathrm{m}^{2}$ aerial weight mat. They also showed that there was no significant change in tensile and compressive strength after the incorporation of these nonwoven mats. Therefore, it can concluded that a better consolidation of these nonwovens is a critical issue to obtain the highest improvement in fracture toughness with minimum loss of in-plane mechanical properties.

Table 4 shows the comparison of the effects of micro and nanofiber nonwoven veils on the mechanical properties of the composites. It can be seen that the Mode-I fracture toughness could be increased significantly by using both micro and nano nonwoven veils. The highest improvement in Mode-I fracture toughness was reported as 718 and $340 \%$ for microfiber and nanofiber PA 66 veils; respectively. Similar to the results of microfiber PA 66 nonwoven interleaving, $G_{\text {IC }}$ values showed an increasing trend with an increase in the amount of nanofibers. The most significant difference between micro and nanofiber interleaving is that microfiber nonwoven PA 66 veils cause a significant reduction in in-plane mechanical properties such as tensile, flexural and compressive strength, while nanofiber nonwoven PA 66 veils had no significant effect on the in-plane mechanical properties. Moreover, the presence of PA 66 nanofibers in the interlaminar region led to an increase in some of the in-plane mechanical properties such as flexural and compressive strengths. Their presence in the interlaminar region provides a win-win situation in which both delamination resistance and in-plane mechanical properties are improved. On the other hand, based on our previous experience, there are some issues that are critical for the success of nanofiber interleaving. Local thickness variations within the nanofiber veil may occur between the primary reinforcing plies. This may cause an increase in the standard deviation which would make it difficult to interpret the test results. Also, it is difficult to produce electrospun nanofibers with standard quality for a long period of time due to variation of PA polymer flow within the nozzles which is directly related to the nanofiber deposition. In addition to productivity issues associated with electrospinning process, highly volatile and toxic solvents such as formic acid and chloroform used for PA 66 polymer may cause serious health hazards and illnesses for workers.

PA 66 nonwoven veils have the highest potential among the other interleaf materials. As reported by Nash et al. [43], they provide an effective way to improve delamination and impact resistance for laminated composite materials and offer various advantages from the manufacturing point-of-view. These nonwovens can be easily integrated into existing autoclave and out-of-autoclave composites by placing them between primary reinforcing fabrics/prepregs prior to 
Table 4

Comparison of microfiber and nanofiber PA 66 interleaving systems.

\begin{tabular}{|c|c|c|c|c|}
\hline Reference & Macro/nano & $\begin{array}{l}\text { Areal weight density } \\
\left(\mathrm{g} / \mathrm{m}^{2}\right)\end{array}$ & Mechanical property & (\% increase or decrease) \\
\hline This study & Macro & 17 & $\begin{array}{l}\text { Mode-I fracture toughness } \\
\text { Tensile modulus/strength } \\
\text { Flexural modulus/strength } \\
\text { Compressive modulus/strength } \\
\text { Impact strength } \\
\text { ILSS }\end{array}$ & $\begin{array}{l}+171 \\
-10.9 /-19.7 \\
-20.7 /-12.62 \\
-2 /-3 \\
+14.7 \\
+22.5\end{array}$ \\
\hline This study & Macro & 50 & $\begin{array}{l}\text { Mode-I fracture toughness } \\
\text { Tensile modulus/strength } \\
\text { Flexural modulus/strength } \\
\text { Compressive modulus/strength } \\
\text { Impact strength } \\
\text { ILSS }\end{array}$ & $\begin{array}{l}+718 \\
-33.5 /-41.2 \\
-27.5 /-24 \\
-12.6 /-13.1 \\
+1.8 \\
+25.1\end{array}$ \\
\hline [27] & $\begin{array}{l}\text { Nano } \\
\text { Nano } \\
\text { Nano }\end{array}$ & $\begin{array}{l}1.5 \\
4.5 \\
9.0\end{array}$ & $\begin{array}{l}\text { Mode-I fracture toughness } \\
\text { Mode-I fracture toughness } \\
\text { Mode-I fracture toughness }\end{array}$ & $\begin{array}{l}+55 \\
+156 \\
+173\end{array}$ \\
\hline [28] & Nano & 1.0 & $\begin{array}{l}\text { Mode-I fracture toughness } \\
\text { Tensile modulus/strength } \\
\text { Flexural modulus/strength } \\
\text { Compressive modulus/strength } \\
\text { Impact strength } \\
\text { ILSS }\end{array}$ & $\begin{array}{l}+49 \\
\text { NSC**/-9.8 } \\
+15.6 / 12.8 \\
\text { NSC/15 } \\
+18 \\
+9.6\end{array}$ \\
\hline [41] & Nano & 1.5 & Mode-I fracture toughness & +45 \\
\hline [42] & Nano & 12.0 & Mode-I fracture toughness & +340 \\
\hline
\end{tabular}

* In the longitudinal direction, NSC: no significant change.

resin infusion/transfer or the simultaneous application of heat and pressure. There are a large number of nonwoven suppliers in the market and therefore one can easily access to the suppliers and distributors of these low-cost materials. Unlike the stitching and weaving processes, the initial investment and maintenance cost of industrial textile machines are not critical which leads to a significant financial savings. Also, there is no risk of contact with hazardous solvents unlike the electrospun nanofiber interleaving.

Although PA 66 nonwovens caused reduction in some in-plane mechanical properties of the composites, this interleaving system can be used in engineering applications subjected to out-of-plane loading in service. Also, instead of using in the whole composite structure, critical areas with high stress concentrations such as near holes, notches and sharp corners can be interleaved by PA66 nonwoven veils for better impact and delamination resistance.

\section{Concluding remarks}

In this study, PA 66 nonwoven veils were used as an interleaf material to improve Mode-I delamination resistance of CF/EP composites. A series of mechanical tests were carried to investigate the effects of PA 66 interleaving systems on the mechanical performance of CF/EP composites. The results showed that the Mode-I fracture toughness could be improved about 350 and $720 \%$ in both initiation and propagation stages of the fracture, respectively, using PA 66 veils. The results also revealed that the ILSS and Charpy impact strength could be increased about $25 \%$ and $15 \%$ respectively by the incorporation of PA 66 veils in the interlaminar region. However, they resulted in an unavoidable compromise in tensile, flexural and compression properties at the expense of reduced carbon fiber volume fraction and increased thickness. The denser PA 66 veils caused a higher reduction in in-plane mechanical properties. $\mathrm{T}_{\mathrm{g}}$ was not affected with the addition of PA 66 veils. The damping ability of the composites improved with the addition of PA66 veils on the interlaminar region of composites.

\section{Acknowledgements}

The authors acknowledge KORDSA Global Inc. of Turkey for providing carbon fabrics. The authors would like to thank Albert Ortega (Director of Technology, Cerex Advanced Fabrics Inc. USA) for supplying the PA 66 veils.

\section{References}

[1] Greenhalgh ES, Rogers C, Robinson P. Fractographic observations on delamination growth and the subsequent migration through the laminate. Compos Sci Technol 2009;69(14):2345-51.

[2] Greenhalgh ES. Failure analysis and fractography of polymer composites. CRC Press; 2009.

[3] Kuwata M. Mechanisms of interlaminar fracture toughness using non-woven veils as interleaf materials (PhD thesis) Queen Mary: University of London; 2010.

[4] Steeves C, Fleck NA. Z-pinned composite laminates: knockdown in compressive strength. In: Proceedings of the 5th Conference of Delamination and Fracture of Composites, London; 18-19 March 1999, p. 60-68.

[5] Reeder JR. Stitching vs. a toughened matrix: compression strength effects. J Compos Mater 1995;29(18):2464-87.

[6] Kang TJ, Lee SH. Effect of stitching on the mechanical and impact properties of woven laminate composite. J Compos Mater 1994;28:1574-87.

[7] Tanzawa Y, Watanabe N, Ishikawa T. FEM simulation of a modified DCB test for 3-D orthogonal interlocked fabric composites. Compos Sci Technol 2001;61(8):1097-107.

[8] Brandt J, Drechsler K, Arendts F-J. Mechanical performance of composites based on various three-dimensional woven-fibre performs. Compos Sci Technol 1996;56:381-6.

[9] Yokozeki T, Iwahori Y, Ishibashi M, Yanagisawa T, Imai K, Arai M, et al. Fracture toughness improvement of CFRP laminates by dispersion of cupstacked carbon nanotubes. Compos Sci Technol 2009;69(14):2268-73.

[10] Ragosta G, Abbate M, Musto P, Scarinzi G, Mascia L. Epoxy-silica particulate nanocomposites: chemical interactions, reinforcement and fracture toughness. Polymer 2005;46(23):10506-16.

[11] Ishai O, Rosenthal H, Sela N, Drukker E. Effect of selective adhesive interleaving on interlaminar fracture toughness of graphite/epoxy composite laminates. Composites 1998;19(1):49-54.

[12] Sela N, Ishai O, Banks-Sills L. The effect of adhesive thickness on interlaminar fracture toughness of interleaved CFRP specimens. Composites 1989;20(3):257-64.

[13] Rechak S, Sun CT. Optimal use of adhesive layers in reducing impact damage in composite laminates. J Reinf Plast Compos 1990;9(6):569-82.

[14] Duarte A, Herszberg I, Paton R. Impact resistance and tolerance of interleaved tape laminates. Compos Struct 1999;47(1-4):753-8.

[15] Lee S-H, Noguchi H, Kim Y-B, Cheong S-K. Effect of interleaved non-woven carbon tissue on interlaminar fracture toughness of laminated composites: Part I - Mode I. J 
Compos Mater 2002;36(18):2153-216.

[16] Kuwata M, Hogg PJ. Interlaminar toughness of interleaved CFRP using non-woven veils: Part 1. Mode-I testing. Compos Part A: Appl Sci Manuf 2011;42(10):1551-9.

[17] Kuwata M, Hogg PJ. Interlaminar toughness of interleaved CFRP using non-woven veils: Part 2. Mode-II testing. Compos Part A: Appl Sci Manuf 2011;42(10):1560-70.

[18] Saz-Orozco BD, Ray D, Stanley WF. Effect of thermoplastic veils on interlaminar fracture Toughness of a Glass Fiber/Vinyl Ester Composite. Polym Compos 2015. http://dx.doi.org/10.1002/pc.23840.

[19] Fitzmaurice K, Ray D, McCarthy MA. PET interleaving veils for improved fracture toughness of glass fibre/low-styrene-emission unsaturated polyester resin composites. J Appl Polym Sci 2015;133(3):42877.

[20] Hamer S, Leibovich H, Green A, Intrater R, Avrahami R, Zussman E, et al. Mode I interlaminar fracture toughness of Nylon 66 nanofibrilmat interleaved carbon/ epoxy laminates. Polym Compos 2011;32(11):1782-9.

[21] O'Donovan K, Ray D, McCarthy MA. Toughening effects of interleaved nylon veils on glass fabric/low-styrene-emission unsaturated polyester resin composites. J Appl Polym Sci 2014;132(7):41462.

[22] Miller SG, Roberts GD, Kohlman LW, Heimann PJ, Pereira JM, Ruggeri CR, 1, Martin RE, McCorkle LS. Impact behavior of composite fan blade leading edge subcomponent with thermoplastic polyurethane interleave. In: Proceedings of 20th International Conference on Composite Materials, Denmark; 19-24 Jul. 2015

[23] Herwan J, Al-Bahkali E, Khalil K, Souli M. Load bearing enhancement of pin joined composite laminates using electrospun polyacrylonitrile nanofiber mats. Arab J Chem 2016;9(2):262-8.

[24] Zhang J, Yang T, Lin T, Wang C. Phase morphology of nanofibre interlayers: critical factor for toughening carbon/epoxy composites. Compos Sci Technol 2012;72(2):256-62.

[25] Li G, Li P, Zhang C, Yu Y, Liu H, Zhang S, et al. Inhomogeneous toughening of carbon fiber/epoxy composite using electrospun polysulfone nanofibrous membranes by in situ phase separation. Compos Sci Technol 2008;68(3-4):987-94.

[26] Sanatgar RH, Borhani S, Ravandi SAH, Gharehaghaji AA. The influence of solvent type and polymer concentration on the physical properties of solid state polymerized PA66 nanofiber yarn. J Appl Polym Sci 2012;126(3):1112-20.

[27] Beckermann G, Pickering K. Mode I and Mode II interlaminar fracture toughness of composite laminates interleaved with electrospun nanofibre veils. Compos Part A: Appl Sci Manuf 2015;72:11-21.

[28] Beylergil B, Tanoglu M, Aktas E. Enhancement of interlaminar fracture toughness of carbon fiber - epoxy composites using polyamide-6,6 electrospun nanofibers. J Appl Polym Sci 2017;45244:1-12.

[29] Palazzetti R, Zucchelli A. Electrospun nanofibers as reinforcement for composite laminates materials-a review. Compos Struct 2017;182:711-27.
[30] Nash NH, Young TM, McGrail PT, Stanley WF. Inclusion of a thermoplastic phase to improve impact and post-impact performances of carbon fibre reinforced thermosetting composites-a review. Mater Des 2015;85:582-97.

[31] De Baere I, Van Paepegem W, Quaresimin M, Degrieck J. On the tension-tension fatigue behaviour of a carbon reinforced thermoplastic part I: limitations of the ASTM D3039/D3479 standard. Polym Test 2011;30(6):625-32.

[32] De Baere I, Van Paepegem W, Hochard C, Degrieck J. On the tension-tension fatigue behaviour of a carbon reinforced thermoplastic part II: evaluation of a dumbbell-shaped specimen. Polym Test 2011;30(6):663-72.

[33] Jones RM. Mechanics of composite materials. McGraw- Hill; 1998.

[34] Barbero EJ. Introduction to composite materials design-second edition. CRC Press; 2011.

[35] ASTM D5528-13. Standard Test Method for Mode I Interlaminar Fracture Toughness of Unidirectional Fiber-Reinforced Polymer Matrix Composites, ASTM International, West Conshohocken, PA; 2013.

[36] Lee S-H, Noguchi H, Kim Y-B, Cheong S-K. Effect of interleaved non-woven carbon tissue on interlaminar fracture toughness of laminated composites: Part II - Mode I. J Compos Mater 2002;36(18):2153-68.

[37] ASTM D4065-12. Standard Practice for Plastics: Dynamic Mechanical Properties: Determination and Report of Procedures. ASTM International, West Conshohocken, PA; 2012.

[38] Ramirez VA, Hogg PJ, Sampson WW. The influence of the nonwoven veil architectures on interlaminar fracture toughness of interleaved composites. Compos Sci Technol 2015;110:103-10.

[39] Nash NH, Young TM, Stanley WF. The reversibility of Mode-I and -II interlaminar fracture toughness after hydrothermal aging of carbon/benzoxazine composites with a thermoplastic toughening interlayer. Compos Struct 2016;152:558-67.

[40] Armstrong-Carroll, Eileen, Cochran, Roland, Improvement of delamination resistance with carbon nonwoven mat interleaves, ASTM Special Technical Publication (1230); 1995, pp. 124-131.

[41] Daelemans L, van der Heijden S, De Baere I, Rahier H, Van Paepegem W, De Clerck K. Nanofibre bridging as a toughening mechanism in carbon/epoxy composite laminates interleaved with electrospun polyamide nanofibrous veils. Compos $\mathrm{Sci}$ Technol 2015;117:244-56.

[42] Hamer S, Leibovich H, Green A, Intrater R, Avrahammi R, Zussman E, et al. Mode interlaminar fracture toughness on Nylon 66 nanofibreilmat interleaved carbon/ epoxy laminates. Polym Compos 2011;32(11):1781-9.

[43] Nash NH, Young TM, Stanley WF. An investigation of the damage tolerance of carbon/benzoxazine composites with a thermoplastic toughening interlayer. Compos Struct 2016;147:25-32. 